\title{
Gravity Waves from Fronts: Parameterization and Middle Atmosphere Response in a General Circulation Model
}

\author{
Martin Charron And Elisa Manzini \\ Max-Planck-Institut für Meteorologie, Hamburg, Germany
}

(Manuscript received 2 November 2000, in final form 30 July 2001)

\begin{abstract}
Current parameterizations of the gravity wave processes that are relevant to middle atmosphere general circulation modeling need to have specified somewhere in the lower atmosphere a number of characteristics of the gravity wave spectrum that arise from different possible gravity wave sources (i.e., the so-called gravity wave source spectrum). The aim of this study is to take into account in the specification of the gravity wave source spectrum a space and time modulation of the gravity wave wind variance and propagation direction associated with the occurrence of frontal systems. Given that fronts are poorly resolved at the truncations commonly used in middle atmosphere models (typically T21-T42), first a method is devised to diagnose conditions that are considered to be the precursor of frontogenesis in a space and time-dependent low-resolution flow. This is achieved by evaluating horizontal isotherm compression due to flow deformation and convergence. Second, when particular conditions are satisfied, the precursor to frontogenesis is used as an indicator of subgridscale gravity wave emission in the model. Third, the wind variance and the propagation direction of the gravity waves at the source level are specified according to empirical evidences of frontal generation of gravity waves. The MAECHAM4 middle atmosphere response to this gravity wave forcing is presented. The study is restricted to fronts since they are thought to be one of the major nonstationary gravity wave sources in the extratropics, other gravity wave source mechanisms being left for later examination.
\end{abstract}

\section{Introduction}

Middle atmosphere general circulation models (MAGCMs) currently used in climate simulations do not explicitly resolve the full spectrum of gravity waves that are recognized to play a fundamental role in driving the middle atmosphere circulation. The horizontal resolution used in the MAGCMs varies typically from T21 to T42 for spectral models and from $2^{\circ}$ to $5^{\circ}$ for gridpoint models, and this is insufficient to resolve vertically propagating small-scale gravity waves with horizontal wavelength smaller than $1000 \mathrm{~km}$. Constraints on the model vertical resolution can also affect the vertical propagation of resolved inertia-gravity waves, presumably with consequences for the eddy driving of zonal wind oscillations in the tropical middle atmosphere (cf. Hamilton et al. 1999). For a recent review on middle atmospheric models and an illustration of their biases, see Pawson et al. (2000).

Gravity waves in the middle atmosphere are important for driving the reversal of the temperature gradient (pole to pole) in the upper mesosphere and the reversal of the jets between the upper mesosphere and the lower ther-

Corresponding author address: Dr. Martin Charron, Max-PlanckInstitut für Meteorologie, Bundesstraße 55, 20146 Hamburg, Germany.

E-mail: charron@dkrz.de mosphere. In addition, gravity wave breaking in the mesosphere contributes to the driving of the large-scale seasonally dependent meridional mass circulation characterized by sinking motions in the polar winter stratosphere. Therefore, the influence of the mesospheric gravity waves may also extend downward and affect the temperature structure of the polar winter stratosphere (Haynes et al. 1991).

In order to take into account the momentum transfer from the lower to the upper atmosphere associated with gravity waves, the common approach in middle atmosphere modeling is to parameterize gravity wave processes. One of the first attempts was to use Rayleigh friction in order to crudely represent the momentum deposition due to gravity wave dissipation in the mesosphere and the associated induced force on the largescale flow (see, e.g., the early work of Leovy 1964, but note that his approach was not meant to specifically represent the effects of gravity waves since their role in the mesosphere was still unknown in the early 1960s). However, Rayleigh friction, that is, linear momentum relaxation, is a restrictive approach since it cannot represent the gravity wave-induced forcing that leads to the reversal of the jets between the upper mesosphere and the lower thermosphere, nor the zonal wind oscillations in the tropical middle atmosphere. In addition, Rayleigh friction may induce spurious feedbacks on the 
large-scale meridional circulation (Shepherd et al. 1996).

More recently, parameterizations have been developed that address the propagation and dissipation of a gravity wave spectrum assumed to arise from a variety of gravity wave sources (Medvedev and Klassen 1995; Hines 1997a,b; Warner and McIntyre 1996, 1997). Such parameterizations have been applied in MAGCMs by McFarlane et al. (1997), Manzini et al. (1997a,b), Manzini and McFarlane (1998), and Medvedev et al. (1998).

One outstanding limitation of current parameterizations of the propagation and dissipation of a gravity wave spectrum is that they do not consider how gravity waves are forced in any detail, with the exception of the assumptions necessary to make the parameterization problem treatable. These parameterizations generally require the specification of a gravity wave spectrum somewhere in the lower atmosphere (hereafter called the gravity wave source spectrum) as an input. The gravity wave source spectrum is therefore relatively unconstrained. Free parameters include, for instance, the launching level of the source spectrum, the gravity wave variance, the direction of propagation, the effective horizontal wavenumber, and the vertical wavenumber power spectral density.

A global climatology of gravity wave sources from which to construct a gravity wave source spectrum is however not available and indeed a subject of active research, but studies of middle atmospheric gravity wave distribution and characteristics on fairly extended regions over the globe are available. Hamilton (1991) found a strong seasonal variation of the gravity wave propagation direction in the height range $28-57 \mathrm{~km}$ in the extratropics using rocketsonde data, consistent with theoretical studies of wave propagation in nonuniform media. Eckermann et al. (1995) suggest, also from rocket soundings, that a strong seasonal dependence of highlatitude gravity wave variance, with maximum in winter and minimum in summer, occurs in the stratosphere. From radiosonde measurements, Allen and Vincent (1995) studied the seasonal and geographical dependence of gravity waves over Australia and established that the gravity wave energy density in the lower stratosphere at midlatitudes seems to be lower in summer than in winter by a factor of two. The phenomena, and their relative importance, at the origin of what seems to be a seasonal and geographical variation of stratospheric gravity wave activity remains, however, debatable. Although the variability of tropospheric gravity wave source mechanisms can indeed represent a nonnegligible factor in explaining some of the stratospheric gravity wave variability, other factors should be considered. In that regard, Alexander (1998) proposed that background wind effects and limitations of observational techniques can modify the interpretation of gravity wave climatological characteristics.

Nonstationary gravity waves that are present in the middle atmosphere can be generated by a number of tropospheric or lower stratospheric meteorological phenomena among which fronts seem to play a relatively important role in the extratropics. Fritts and Nastrom (1992) calculated from aircraft measurements that total wind variance on segments of 64 and $256 \mathrm{~km}$ in the upper troposphere/lower stratosphere can increase to -3-6 $\mathrm{m}^{2} \mathrm{~s}^{-2}$ when frontal activity is occurring in the troposphere, as compared with a background variance of the order of $0.5-1.5 \mathrm{~m}^{2} \mathrm{~s}^{-2}$. In their data analysis, fronts seem to generate gravity wave variance values comparable to jet stream excitation, but somewhat less than topographic excitation. Eckermann and Vincent (1993) used VHF radar observations over Southern Australia and found that horizontal wind variance bursts reaching up to $10-100 \mathrm{~m}^{2} \mathrm{~s}^{-2}$ were generated in the upper troposphere/lower stratosphere during the passage of cold fronts. According to these authors, this dramatic increase in variance is caused by gravity waves generated by frontal systems. High resolution numerical simulations (e.g., Griffiths and Reeder 1996; Reeder and Griffiths 1996) also strongly suggest that frontal systems can be an important source of gravity waves.

This work is a first attempt to address the problem of how to relate part of the source spectrum of a gravity wave parameterization to frontal systems. Given that MAGCMs at T21-T42 truncations poorly resolve the frontal systems themselves, a possible approach consists in determining precise resolved flow conditions that can be precursors of gravity wave emission in the real atmosphere. This approach will be taken here with the aim of linking subgrid-scale gravity wave emission to conditions that could lead to frontogenesis, were the model resolution higher. In particular, the gravity wave emission assumed to be associated with frontal systems is linked to a model-resolved tropospheric flow configuration that describes isotherm compression by wind deformation and convergence and that can be interpreted as favorable to frontogenesis.

The purposes of this work are first to establish a simple method for representing gravity waves forced by frontal systems and second to evaluate the impact of spatial and temporal variations of the tropospheric gravity wave source distribution on the middle atmospheric mean circulation by taking into account frontal systems. Other gravity wave source mechanisms are left for further examination in following studies.

The vast majority of the gravity waves present in the stratosphere and mesosphere being of tropospheric origin, a change, in a climatological sense, of tropospheric variability (e.g., a change in frontogenesis occurrence) could possibly infer a change in gravity wave source climatology. The approach used in this work is to relate at least part of the parameterized gravity wave source spectrum to the resolved flow in the model. It will therefore take into account possible changes of the simulated tropospheric variability in the gravity wave forcing. An additional link between the lower and the middle atmosphere that addresses the role of tropospheric syn- 
optic activity in the middle atmospheric circulation is consequently incorporated into the general circulation model.

The paper is organized as follows. Section 2 describes the method applied in this study of linking gravity wave emission to fronts, independently of the specific parameterization of gravity waves used. Section 3 presents the general circulation model employed and the design of the simulations performed in order to establish the proposed method and to evaluate the response of the middle atmosphere circulation. Results are reported and discussed in sections 4 and 5. A summary and some conclusions are drawn in section 6 .

\section{Gravity waves from fronts: Parameterization}

\section{a. Linking the resolved tropospheric circulation to fronts}

Frontogenesis is most likely to occur when a strong deformation wind field acts to increase the horizontal temperature gradient. In two dimensions (latitude-longitude), the evolution of the horizontal potential temperature gradient is given by the so-called frontogenesis function (Miller 1948; Hoskins 1982)

$$
\begin{aligned}
\frac{1}{2} \frac{D|\nabla \theta|^{2}}{D t}= & -\left(\frac{1}{a \cos \phi} \frac{\partial \theta}{\partial \lambda}\right)^{2}\left[\frac{1}{a \cos \phi} \frac{\partial u}{\partial \lambda}-\frac{v \tan \phi}{a}\right] \\
& -\left(\frac{1}{a} \frac{\partial \theta}{\partial \phi}\right)^{2}\left[\frac{1}{a} \frac{\partial v}{\partial \phi}\right]-\left(\frac{1}{a \cos \phi} \frac{\partial \theta}{\partial \lambda}\right)\left(\frac{1}{a} \frac{\partial \theta}{\partial \phi}\right) \\
& \times\left[\frac{1}{a \cos \phi} \frac{\partial v}{\partial \lambda}+\frac{1}{a} \frac{\partial u}{\partial \phi}+\frac{u \tan \phi}{a}\right]
\end{aligned}
$$

when vertical motion, diabatic effects, and diffusion are neglected (thus, $D / D t$ is a horizontal Lagrangian derivative on the sphere). In Eq. (2.1), $\theta$ is the potential temperature, $u$ is the zonal wind, $v$ is the meridional wind, $\lambda$ is the longitude, and $\phi$ is the latitude. It is easy to show that Eq. (2.1) can be rewritten as a function of two deformation fields and divergence, but is independent of the vertical component of vorticity. High values of the right-hand side of Eq. (2.1) at some selected vertical level can be interpreted as a possible precursor to frontogenesis when $\theta, u$, and $v$ are interpreted as large-scale (or resolved) fields. In the context of a numerical simulation at relatively low resolution, frontogenesis may not occur, but high values (greater than some selected threshold) of the quantity defined by Eq. (2.1) could indicate that it would have occurred at a sufficiently high resolution. The approach followed here assumes that the frontogenesis function calculated at a single vertical level in the troposphere suffices to determine the possible occurrence of frontogenesis.

\section{b. Frontogenesis function versus fronts}

In order to verify if Eq. (2.1) can actually reproduce the occurrence of frontal zones and to compare their locations with those given by the frontogenesis function at a lower resolution, frontal systems would have to be explicitly diagnosed from very high horizontal resolution simulations of a global model. The availability of the operational European Centre for Medium-Range Weather Forecasts (ECMWF) analysis, at T319 horizontal truncation and 31 vertical levels ranging from the surface to $10 \mathrm{hPa}$ allows to perform such an evaluation. Low-level frontal regions are diagnosed from the ECMWF analysis dataset (reduced at T213) from the horizontal temperature gradient

$$
\left|\nabla_{z} T^{\prime}\right| \geq 2 \mathrm{~K}(100 \mathrm{~km})^{-1}
$$

at a height corresponding to about $800 \mathrm{hPa}$ in the absence of topography for the period April 1998 to February 1999. The presence of fronts has not been considered north of $75^{\circ} \mathrm{N}$ and south of $75^{\circ} \mathrm{S}$ because of the high sensitivity to anomalies in the data assimilation process at these latitudes that can render the analysis data not trustful. Given that the database is used with a hybrid sigma-pressure vertical coordinate, the gradient is obtained from

$$
\boldsymbol{\nabla}_{z} T^{\prime}=\boldsymbol{\nabla}_{\eta} T^{\prime}-\frac{\partial T^{\prime}}{\partial \Phi} \nabla_{\eta} \Phi .
$$

The derivatives are made in gridpoint space with a finitedifference scheme precise to order 2 (higher-order schemes have been tested but with no significant changes in the results). Here, $T^{\prime}$, the temperature departure from the monthly mean average, is used instead of the actual temperature in order to neglect stationary patterns that might be more representative of land-sea contrasts than frontal dynamics. The threshold of $2 \mathrm{~K}(100 \mathrm{~km})^{-1}$ has been determined empirically by choosing a value of about 2.5 standard deviations away from the temperature gradient space and time mean.

The right-hand side of Eq. (2.1) is calculated on a hybrid sigma-pressure level near $600 \mathrm{hPa}$ using the same ECMWF analysis dataset, but truncated at T42 resolution [the horizontal derivatives being calculated as in Eq. (2.3)], and can be compared with the front positions obtained from the T213 resolution. The choice of a different vertical level for comparing fronts predicted by the frontogenesis function at T42 $(\sim 600 \mathrm{hPa})$ and actual fronts at T213 $(\sim 800 \mathrm{hPa})$ is justified as follows: since the frontogenesis function evaluated at a single level (presumably the level at which gravity waves emerge) will be used as a gravity wave source indicator in the simulations described in section 3, and supposing that gravity waves emerge somewhat above the low-level frontal regions, it is important to know whether or not the frontogenesis function diagnosed in the middle troposphere is capable of indicating the presence of frontal regions below. Figure 1 shows how the right-hand side 
Fronts T213 Jan 1519991200 GMT

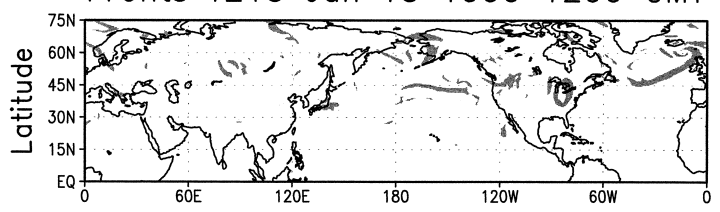

Frontogen. funct. T42 Jan 1519991200 GMT

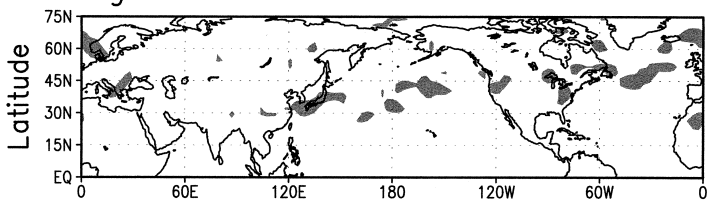

Fronts T213 July 1519981200 GMT

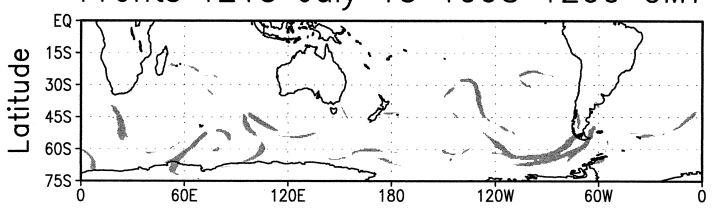

Frontogen. funct. T42 July 1519981200 GMT

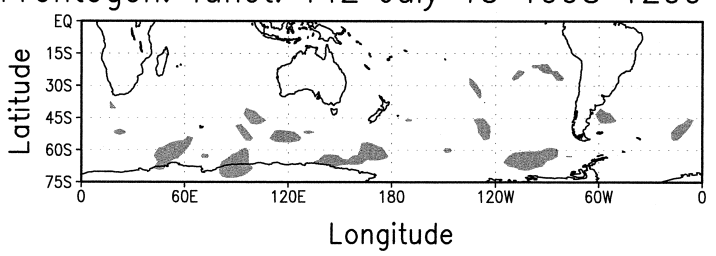

FIG. 1. (upper panel) Northern Hemispheric frontal zones as computed using $\left|\boldsymbol{\nabla}_{z} T\right| \geq 2 \mathrm{~K}(100 \mathrm{~km})^{-1}$ on the ECMWF analyses at T213 1200 UTC 15 Jan 1999 at around $800 \mathrm{hPa}$ (sigma-pressure hybrid level). (second panel) Diagnosed fronts as computed using the right-hand side of Eq. (2.1) on the ECMWF analyses at T42 for the same time, but at around $600 \mathrm{hPa}$. The gray regions indicate values greater than $0.1 \mathrm{~K}^{2}(100 \mathrm{~km})^{-2} \mathrm{~h}^{-1}$. (bottom two panels) Similar to the first and second panel, respectively, but the Southern Hemisphere is shown at 1200 UTC $15 \mathrm{Jul} 1998$.

of Eq. (2.1) can reproduce the occurrence of fronts when a minimum threshold of $0.1 \mathrm{~K}^{2}(100 \mathrm{~km})^{-2} \mathrm{~h}^{-1}$ is employed to isolate regions of expected frontogenesis. As a comparison, the initial conditions of two-dimensional simulations of fronts performed by Griffiths and Reeder (1996) give a value of $0.07 \mathrm{~K}^{2}(100 \mathrm{~km})^{-2} \mathrm{~h}^{-1}$, indicating that the threshold used in the present work is relatively stringent. The frontogenesis function calculated at a relatively low resolution can indeed be a good front indicator. See, for instance, the occurrence of fronts just over Japan, across the northeast Pacific and the northern Atlantic, from North America to Scandinavia. In the Southern Hemisphere, frontal activity is diagnosed from both methods southwest of Australia and west of South America.

A simple alternative to the frontogenesis function would have been to use the modulus of the temperature gradient itself [but, e.g., at a smaller threshold value than $2 \mathrm{~K}(100 \mathrm{~km})^{-1}$ ] as a front indicator in the lowresolution model, but this approach does not take ad- vantage of the additional information provided by the large-scale wind deformation and convergence that is crucial to frontogenesis. This is why the use of the frontogenesis function has been preferred.

\section{c. Gravity wave emission from the frontogenesis function}

The parameters that are necessary to completely specify a spectrum of gravity waves emerging from frontal disturbances being mostly unknown, the approach followed here is based on two empirical pieces of evidence gathered from measurements and high-resolution numerical simulations: bursts of high horizontal wind variance linked to gravity wave motion are observed on the passage of fronts (Fritts and Nastrom 1992; Eckermann and Vincent 1993), and gravity waves are emitted, at least, in the cross-front directions (Griffiths and Reeder 1996; Reeder and Griffiths 1996). According to these authors, the cross-front circulation and the resulting isentrope oscillations could be the mechanism producing the gravity waves, although it is not clear whether low-level fronts or high-level fronts are responsible for the stratospheric gravity waves. Based on these observations and the high-resolution idealized numerical results; the total variance, the orientation of propagation, and the launching height of the gravity wave source spectrum are specified in the following way:

1) At the launching level $\eta_{\mathrm{L}}$, located around $600 \mathrm{hPa}$, the right-hand side of Eq. (2.1) is evaluated. This fixed launching level is chosen a priori in the scope of representing gravity waves that are emerging from low-level fronts.

2) If the threshold of $0.1 \mathrm{~K}^{2}(100 \mathrm{~km})^{-2} \mathrm{~h}^{-1}$ at some horizontal grid point and time step is reached, a subgrid-scale total gravity wave wind variance of $4 \mathrm{~m}^{2}$ $\mathrm{s}^{-2}$ is imposed at that horizontal grid point and time step. The horizontal propagation directions of the equally bipartitioned vertical flux of horizontal momentum in a frame of reference moving with the flow are chosen to be given by the two cross-front directions $\alpha_{1}$ and $\alpha_{2}$, where

$$
\alpha_{1}=\arctan \left(\frac{\cos \phi \partial \theta / \partial \phi}{\partial \theta / \partial \lambda}\right) \quad \alpha_{2}=\alpha_{1}+\pi .
$$

3) If the threshold is not reached, an isotropic total gravity wave wind variance of $0.64 \mathrm{~m}^{2} \mathrm{~s}^{-2}$ is instead imposed with the aim of representing other possible gravity wave sources.

The remaining free parameters of the gravity wave source spectrum will therefore depend only on the requirements of the specific parameterization of the propagation and dissipation of the gravity wave spectrum used in the general circulation model. The specified value of $4 \mathrm{~m}^{2} \mathrm{~s}^{-2}$ at launching level when the frontogenesis 
function reaches the threshold has been chosen empirically so that variances emerging from the troposphere generally agree with values reported in Fritts and Nastrom (1992). As noted earlier, high-level fronts (close to the tropopause) are also possible generators of gravity waves. However, given the uncertainty on the frontal gravity wave launching level in the high-resolution numerical simulations (Griffiths and Reeder 1996; Reeder and Griffiths 1996), sensitivity tests on the frontal gravity wave launching level have not been considered here.

\section{General circulation model and design of the simulations}

The MAECHAM4 model is the extension to the mesosphere of the spectral ECHAM4 general circulation model of the atmosphere (Roeckner et al. 1996). For a description of the MAECHAM4 model, the reader is referred to Manzini et al. (1997a) and Manzini and McFarlane (1998) and references therein. For an evaluation of the large-scale transport, see Manzini and Feichter (1999). In the standard configuration of the MAECHAM4 model, the vertical domain ranges from the surface to $0.01 \mathrm{hPa}(\sim 80 \mathrm{~km})$, discretized on a hybrid sigma-pressure coordinate system with 39 vertical layers. Triangular spectral truncation at either wavenumber 30 (T30) or 42 (T42) is used. Two methods are used in combination to parameterize gravity wave processes: The orographic waves are treated by a modification of the McFarlane (1987) parameterization, while gravity waves assumed to give rise to a continuous broadband spectrum are parameterized following Hines (1997a,b).

In order to be used in a general circulation model, a number of simplifications needs to be considered in any parameterization of the effects of gravity waves. For the Hines parameterization, these simplifications include the absence of Coriolis and nonhydrostatic effects, as well as back reflection, implying that the gravity wave spectrum can be written as a function of vertical wavenumber only. The horizontal wavenumber dependence of the spectrum is integrated out, and an equivalent (relatively unconstrained) horizontal wavenumber $K^{*}$ is used to characterize the horizontal scale of the gravity waves. In the parameterization, Doppler spreading by nonlinear wave-wave interactions is assumed to play an essential role in the dissipation of the upward propagating gravity waves. Wave breaking is represented by imposing an upper limit to the range of vertical wavenumbers in the spectrum (a "cutoff" wavenumber) that can propagate above the altitude considered. Any spectral element that is moved to a vertical wavenumber greater than the cutoff wavenumber due to Doppler spreading, background wind variations, and/or to instability of the whole spectrum is considered to be dissipated and is removed, thus producing momentum flux deposition. The momentum flux carried by the waves is controlled by specifying gravity wave horizontal wind variances in each azimuthal direction at a given source level.

The reference simulation, hereafter labeled GWRF1, is carried out with the MAECHAM4 model with the parameterization of the gravity wave emission from frontal disturbances applied to the input source spectrum of the Hines parameterization. The GWRF1 employs T30 truncation and includes a few other modifications to the input source spectrum with respect to the configuration used by Manzini and McFarlane (1998), as detailed below. In addition, three sensitivity simulations have been carried out, respectively, labeled GWRF2, UNI1, and UNI2 and also described below. The results from the GWRF1, UNI1, and UNI2 simulations are each one from 12-yr integrations (after spinup from an earlier model version), while results from the GWRF2 simulation are from a 5-yr integration. Climatological boundary conditions, for example, sea surface temperature (Gates 1992), have been used for all simulations. Seasonal and diurnal cycles are included in the radiative transfer calculations for all cases.

\section{a. GWRF1 and GWRF2 simulations: Gravity wave source from resolved flow}

The GWRF1 and GWRF2 simulations differ only for the horizontal resolution employed. The shorter T42 integration is performed in order to test the sensitivity to horizontal resolution of the method used to diagnose the possibility of frontogenesis, given that the middle atmosphere sensitivity to the increase in horizontal resolution from T30 to T42 has been found to be modest in previous MAECHAM4 simulations (see http:// www.mpimet.mpg.de/Depts/Modell/MA/salzau.html).

In order to simplify the intercomparison between the two sets of simulations, the latitudinal dependence of the effective horizontal wavenumber $K^{*}$, included in the standard MAECHAM4 model (see Manzini and McFarlane 1998), has been here neglected. In the current simulations, the constant effective horizontal wavenumber has been chosen to be

$$
K^{*}=5 \times 10^{-5} \mathrm{~m}^{-1} \approx 2 \pi(126 \mathrm{~km})^{-1} .
$$

A further modification to the standard configuration of the Hines parameterization used so far in the MAECHAM4 model is the inclusion of a lower bound to the vertical wavenumber power spectral density, set to $2 \pi$ $(20 \mathrm{~km})^{-1}$, in order to neglect gravity waves with unrealistically large vertical wavelengths. Simulation tests have shown that the sensitivity to the introduction of the lower bound is almost negligible and restricted to the upper mesosphere, presumably because shorter vertical wavelengths dominate the momentum flux deposition below the model top at $80 \mathrm{~km}$, as suggested by the results of McLandress (1997). The influence of the lower bound in the vertical wavenumber power spectral density is instead expected to be noticeable if the model top were to be raised to the lower thermosphere. 


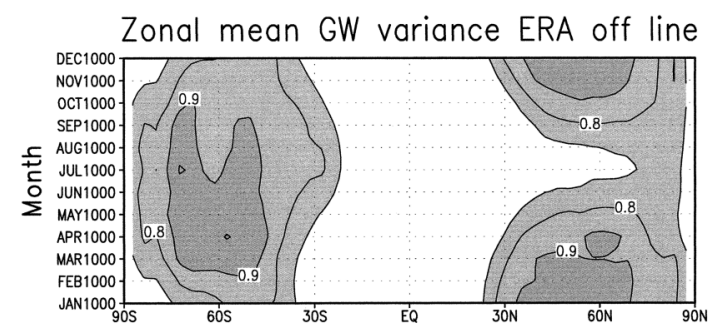

Zonal mean GW variance LH GWRF1

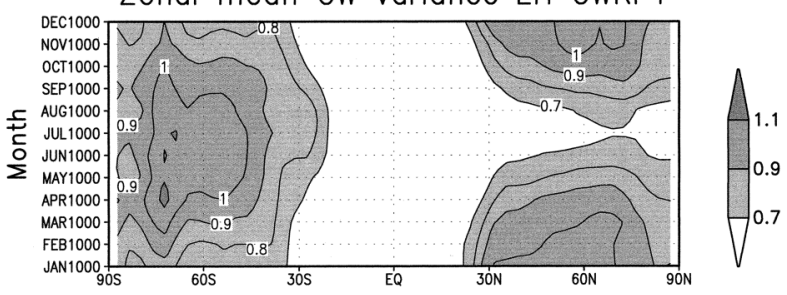

Zonal mean GW variance LH GWRF2

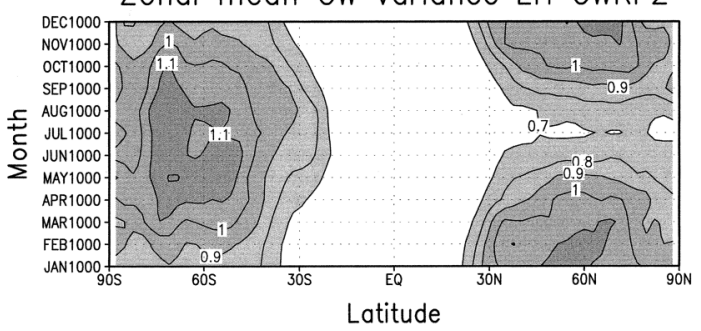

FIG. 2. (upper panel) Fifteen-year ensemble mean of the monthly zonal mean total gravity wave wind variance $\left(\mathrm{m}^{2} \mathrm{~s}^{-2}\right)$ obtained from an offline calculation from the ECMWF reanalyses at T30 and at 600 hPa. (middle) and (lower panels) Twelve-year and 5-yr ensemble means of the monthly zonal mean total gravity wave wind variance $\left(\mathrm{m}^{2} \mathrm{~s}^{-2}\right)$ at the launching level (near $600 \mathrm{hPa}$ ) obtained from the GWRF1 and GWRF2 experiments, respectively. The contour interval is $0.1 \mathrm{~m}^{2} \mathrm{~s}^{-2}$.

In the current simulations, the slope of the power spectral density at the launching height is specified to be +1 for vertical wavenumbers smaller than the cutoff wavenumber.

The level $\eta_{\mathrm{L}}$ at which the gravity wave source spectrum is specified and the frontogenesis function evaluated, is chosen to be the eigth full hybrid level above the surface (at $600 \mathrm{hPa}$ in the absence of topography). As the GWRF1 and GWRF2 simulations evolve, the right-hand side of Eq. (2.1) is computed at each grid point and time step at the $\eta_{\mathrm{L}}$ level in order to determine whether or not conditions favorable to frontogenesis are met and to specify the gravity wave variance and direction of propagation accordingly (see section 2c).
Note that in the right-hand side of Eq. (2.1) the horizontal derivatives are obtained as in Eq. (2.3), but the geopotential is replaced by pressure.

In the standard configuration of the Hines parameterization, eight equally spaced azimuthal directions are employed as directions of wave propagation. This design is carried over for the current simulations, except for the case when conditions favorable to frontogenesis are met and therefore only two azimuths are used at the launching height, that is, those in the vicinity of $\alpha_{1}$ and $\alpha_{2}$ introduced in section 2c.

\section{b. UNI1 and UNI2 simulations: Uniform gravity wave variance at launching level}

The UNI1 and UNI2 simulations are sensitivity tests and serve as a mean of directly evaluating the impact of including a representation of fronts in the gravity wave source. Both UNI1 and UNI2 simulations are carried out at $\mathrm{T} 30$ truncations. They share the new features of the GWRF1 and GWRF2 configuration of the source spectrum concerning the launching level $\eta_{L}$, the constant $K^{*}$, and the lower bound to the vertical wavenumber. UNI1 and UNI2 also share the standard configuration, that is, the slope of the vertical wavenumber power spectral density and the number of azimuthal directions for gravity wave propagation.

The source spectrum of the UNI1 simulation is assumed to be isotropic. The total gravity wave variance at the launching level is set to $0.64 \mathrm{~m}^{2} \mathrm{~s}^{-2}$, uniform in space and constant in time. The UNI1 source spectrum would therefore be identical to the one specified in simulations GWRF1 and GWRF2 if the minimum threshold of the frontogenesis function was never reached in these latter simulations. The only nonuniformity in the source spectrum used in the UNI1 simulation arises from the dependence of the cutoff vertical wavenumber on the buoyancy frequency at the launching level.

The source spectrum of the UNI2 simulation is specified as in UNI1, but the total gravity wave variance at the launching level is here set to $1 \mathrm{~m}^{2} \mathrm{~s}^{-2}$. Such a value is very close to the maximum zonal and monthly mean total variance at launching level located at middle and high latitudes that is diagnosed in simulation GWRF1, as is shown in the following section.

The total gravity wave variances used in the UNI1 or UNI2 simulations are therefore, respectively, close to the smallest and the largest average variances produced in GWRF1. The comparison of the GWRF1 simulation with either the UNI1 or UNI2 simulation will

TABLE 1. Name and brief description of the four performed simulations.

\begin{tabular}{lccc}
\hline \hline Label & Resolution & Integration time & Total gravity wave wind variance at source level \\
\hline GWRF1 & T30 & $12 \mathrm{yr}$ & Frontal: $4 \mathrm{~m}^{2} \mathrm{~s}^{-2}$, nonfrontal: $0.64 \mathrm{~m}^{2} \mathrm{~s}^{-2}$ \\
GWRF2 & T42 & $5 \mathrm{yr}$ & Frontal: $4 \mathrm{~m}^{2} \mathrm{~s}^{-2}$, nonfrontal: $0.64 \mathrm{~m}^{2} \mathrm{~s}^{-2}$ \\
UNI1 & T30 & $12 \mathrm{yr}$ & Uniform, constant, and isotropic: $0.64 \mathrm{~m}^{2} \mathrm{~s}^{-2}$ \\
UNI2 & T30 & Uniform, constant, and isotropic: $1 \mathrm{~m}^{2} \mathrm{~s}^{-2}$ \\
\hline
\end{tabular}



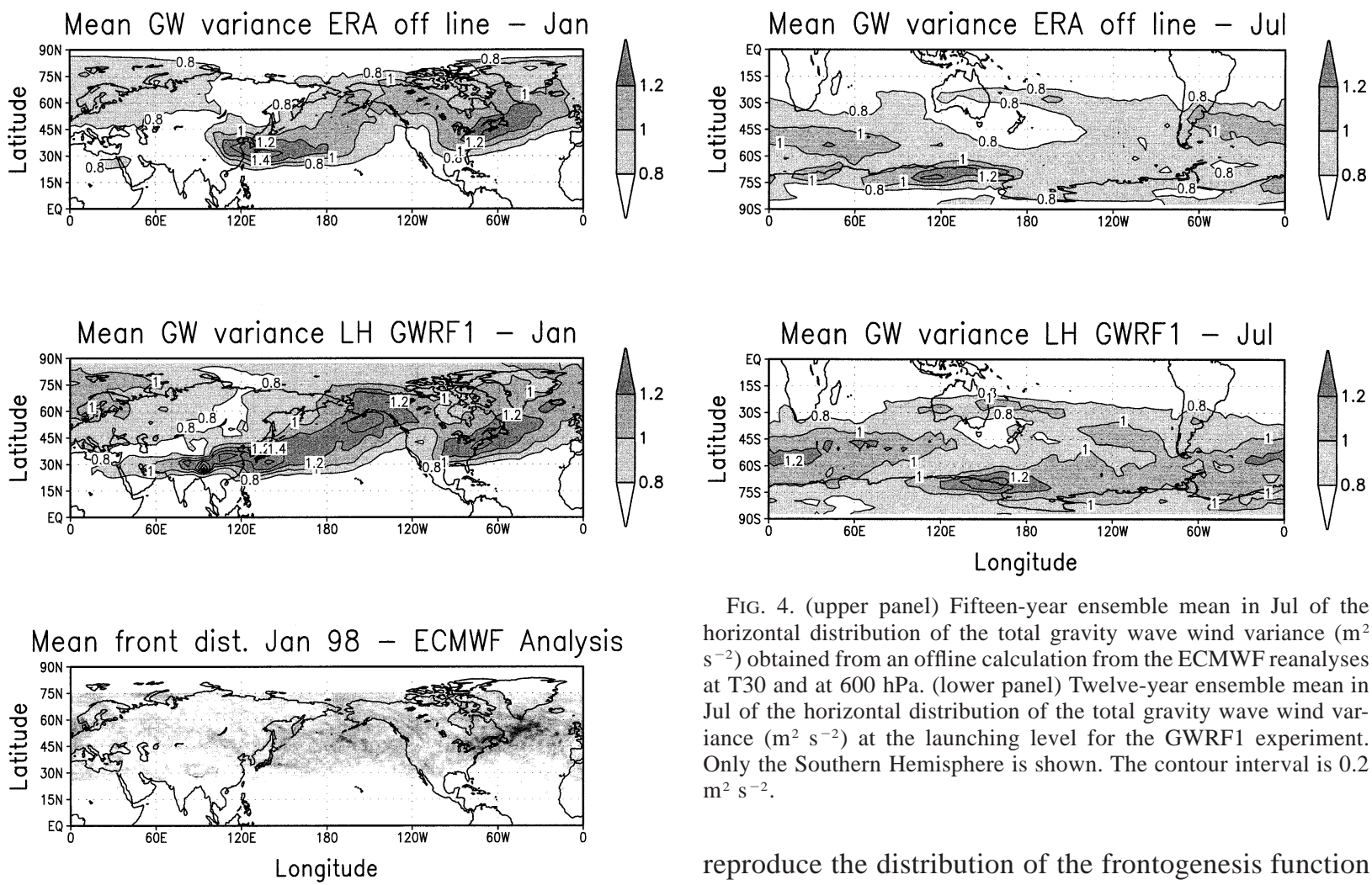

FIG. 3. (upper panel) Fifteen-year ensemble mean in Jan of the horizontal distribution of the total gravity wave wind variance $\left(\mathrm{m}^{2}\right.$ $\mathrm{s}^{-2}$ ) obtained from an offline calculation from the ECMWF reanalyses at T30 and at $600 \mathrm{hPa}$. (middle panel) Twelve-year ensemble mean in Jan of the horizontal distribution of the total gravity wave wind variance $\left(\mathrm{m}^{2} \mathrm{~s}^{-2}\right)$ at the launching level for the GWRF1 experiment. (lower panel) Mean horizontal front distribution in Jan 1999 obtained using $\left|\boldsymbol{\nabla}_{z} T\right| \geq 2 \mathrm{~K}(100 \mathrm{~km})^{-1}$ from the ECMWF analyses at T213 and near $800 \mathrm{hPa}$. On the upper and middle panels, the contour internal is $0.2 \mathrm{~m}^{2} \mathrm{~s}^{-2}$. Only the Northern Hemisphere is shown.

consequently illustrate different aspects of the sensitivity of the model extratropical middle atmosphere circulation to the introduction of a space and time gravity wave source variability.

Table 1 summarizes some relevant specificities of the four simulations performed in the present study.

\section{Gravity wave distributions}

\section{a. Launching level and lower stratosphere}

Given that the gravity wave wind variance produced in the simulations GWRF1 and GWRF2 depends on the resolved flow, namely, on the distribution of the frontogenesis function given by Eq. (2.1), it is important that the processes leading to the possible occurrence of fronts (i.e., synoptic baroclinic eddies) are reasonably simulated in the model. This is usually the case at T30 truncation, although systematic biases in the model may affect the space and time eddy statistics. In order to evaluate to what extent the current model is able to

FIG. 4. (upper panel) Fifteen-year ensemble mean in Jul of the horizontal distribution of the total gravity wave wind variance $\left(\mathrm{m}^{2}\right.$ $\mathrm{s}^{-2}$ ) obtained from an offline calculation from the ECMWF reanalyses at T30 and at $600 \mathrm{hPa}$. (lower panel) Twelve-year ensemble mean in Jul of the horizontal distribution of the total gravity wave wind variance $\left(\mathrm{m}^{2} \mathrm{~s}^{-2}\right)$ at the launching level for the GWRF1 experiment. Only the Southern Hemisphere is shown. The contour interval is 0.2 $\mathrm{m}^{2} \mathrm{~s}^{-2}$.

reproduce the distribution of the frontogenesis function given by Eq. (2.1), an offline version of the code evaluating the gravity wave variance at $600 \mathrm{hPa}$ based on the frontogenesis function as described in section 2 has been applied on $15 \mathrm{yr}$ of ECMWF reanalyses sampled twice a day at truncation T30.

The ensemble mean of the monthly zonal mean gravity wave variance computed from the ECMWF reanalyses at $600 \mathrm{hPa}$ and from the GWRF1 at the launching level are compared in Fig. 2 (upper and middle panels). Figure 2 indicates that the seasonal modulation and the interhemispheric asymmetry (northern summer values lower than southern summer ones) are well reproduced by the model at resolutions T30, but that the winter values of the frontogenesis function are slightly overestimated by the model at middle and high latitudes. The double peak structure in the winter Southern Hemisphere at $50^{\circ}$ and $70^{\circ} \mathrm{S}$ clearly seen in the case of the ECMWF reanalyses is also present, but less accentuated, in the GWRF1 simulation. As it may be expected, for both the ECMWF and GWRF1 cases, the variance is below $0.7 \mathrm{~m}^{2} \mathrm{~s}^{-2}$ in the tropical regions; that is, the flow conditions are not favorable to frontogenesis.

The lower panel of Fig. 2 depicts the ensemble mean of the monthly zonal mean gravity wave variance at launching level for the experiment GWRF2 (truncation T42). The seasonal and latitudinal variations of the GWRF1 variance are very similar to those of the GWRF2 variance, although slightly larger values are found during both the northern and southern winter. The larger GWRF2 variance means that the occurrence of relatively high values of the frontogenesis function in- 
TABLE 2a. Twelve-year ensemble mean of the monthly zonal mean azimuthal distribution of the vertical flux of horizontal momentum carried by gravity waves for experiment GWRF1 at launching level in Jan for extratropical latitude bands of $15^{\circ}$. Values exceeding 0.160 are in bold.

\begin{tabular}{cccccccc}
\hline \hline Direction & $90^{\circ}-75^{\circ} \mathrm{N}$ & $75^{\circ}-60^{\circ} \mathrm{N}$ & $60^{\circ}-45^{\circ} \mathrm{N}$ & $45^{\circ}-30^{\circ} \mathrm{N}$ & $30^{\circ}-45^{\circ} \mathrm{S}$ & $45^{\circ}-60^{\circ} \mathrm{S}$ & $60^{\circ}-75^{\circ} \mathrm{S}$ \\
\hline E & 0.125 & 0.110 & 0.110 & 0.107 & 0.082 & 0.109 & 0.119 \\
NE & 0.126 & 0.120 & 0.112 & 0.125 & 0.096 & 0.128 & 0.130 \\
N & 0.124 & 0.147 & 0.139 & 0.157 & $\mathbf{0 . 2 0 0}$ & 0.144 & 0.129 \\
NW & 0.125 & 0.123 & 0.140 & 0.110 & 0.121 & 0.118 & 0.122 \\
W & 0.125 & 0.110 & 0.110 & 0.107 & 0.082 & 0.109 & 0.119 \\
SW & 0.126 & 0.120 & 0.112 & 0.125 & 0.096 & 0.128 & 0.130 \\
S & 0.124 & 0.147 & 0.139 & 0.157 & $\mathbf{0 . 2 0 0}$ & 0.144 & 0.129 \\
SE & 0.125 & 0.123 & 0.140 & 0.110 & 0.121 & 0.118 \\
\hline
\end{tabular}

creases with resolution as smaller scales are allowed to develop. This behavior suggests that in order to keep the same value of gravity wave momentum flux emission as in experiment GWRF1, the threshold of the frontogenesis function beyond which gravity wave emission by fronts is allowed should be slightly increased when using a truncation T42. Nevertheless, the increase in gravity wave wind variance when going from T30 to T42 truncation is relatively modest and suggests that the threshold employed here for predicting frontogenesis is robust to resolution changes of this order.

The horizontal distribution of the gravity wave variance computed from the ECMWF dataset at $600 \mathrm{hPa}$ and from the GWRF1 simulation at the launching level is shown in Fig. 3 (upper and middle panel, respectively) for the January ensemble mean. The bottom panel of Fig. 3 shows the January 1999 mean horizontal frontal distribution at around $800 \mathrm{hPa}$ obtained from the ECMWF analyses at truncation T213. For all three datasets, regions of high variance are located over Eastern Asia-Northern Pacific and from Eastern North America to the Northern Atlantic. These regions are indicative of enhanced frontogenesis and correspond to the observed storm tracks (Blackmon 1976; Blackmon et al. 1984; Hoskins and Valdes 1990; Kageyama et al. 1999). Consequently, it appears that the synoptic activity is correctly simulated by the model troposphere [see Kageyama et al. (1999) for an evaluation of the ECHAM3 model on this matter]. Although the two main frontogenesis regions in January coincide fairly well on the three panels, the frontal distribution over the eastern coast of Asia diagnosed from the ECMWF analysis (lower panel) seems somewhat less dense than the one predicted from the frontogenesis function (lower and middle panels). But care is needed when comparing with the lower panel of Fig. 3 since it is based on one single month of data sampled twice daily. Note also the anomalous spot of high gravity wave variance diagnosed by the model situated over the Himalayas (middle panel) that is certainly due to an overestimation induced by strong orography of the derivatives in Eq. (2.1). Indeed, an offline calculation of the frontogenesis function on the GWRF1 data at the constant pressure level of 600 $\mathrm{hPa}$ (not shown) does not reproduce this anomaly, suggesting that the last term on the right-hand side of Eq. (2.3) might not suffice to correct completely the influence of orography in the derivative evaluations when the orography slope is very strong. Such anomalous spots do not occur anywhere else.

Figure 4 is similar to Fig. 3, but illustrates the Southern Hemisphere in July. The locations of high and low mean gravity wave variance regions in experiment GWRF1 are generally in agreement with the offline calculation on the ECMWF reanalyses, but with a general model overestimation between $40^{\circ}$ and $70^{\circ} \mathrm{S}$. In particular, the estimated relatively low occurrence region of frontogenesis centered over New Zealand (upper panel) is captured, although it is slightly smaller, in experiment GWRF1 (lower panel). Also, the region of relatively high variance values between $60^{\circ} \mathrm{W}$ and $70^{\circ} \mathrm{E}$ near $50^{\circ} \mathrm{S}$ diagnosed from the reanalyses extends almost around a longitude circle in experiment GWRF1, although a relative maximum is discernible between $30^{\circ} \mathrm{W}$ and $50^{\circ} \mathrm{E}$ around $50^{\circ} \mathrm{S}$. The relative maximum located between

TABLE 2b. Twelve-year ensemble mean of the monthly zonal mean azimuthal distribution of the vertical flux of horizontal momentum carried by gravity waves for experiment GWRF1 at $70 \mathrm{hPa}$ in Jan for extratropical latitude bands of $15^{\circ}$. Values exceeding 0.160 are in bold.

\begin{tabular}{cccccccc}
\hline \hline Direction & $90^{\circ}-75^{\circ} \mathrm{N}$ & $75^{\circ}-60^{\circ} \mathrm{N}$ & $60^{\circ}-45^{\circ} \mathrm{N}$ & $45^{\circ}-30^{\circ} \mathrm{N}$ & $30^{\circ}-45^{\circ} \mathrm{S}$ & $45^{\circ}-60^{\circ} \mathrm{S}$ & $60^{\circ}-75^{\circ} \mathrm{S}$ \\
\hline E & 0.097 & 0.059 & 0.031 & 0.006 & 0.008 & 0.044 & 0.060 \\
NE & 0.106 & 0.091 & 0.055 & 0.028 & 0.019 & 0.068 & 0.092 \\
N & 0.128 & $\mathbf{0 . 1 7 1}$ & $\mathbf{0 . 1 7 2}$ & $\mathbf{0 . 2 0 0}$ & 0.152 & 0.134 & 0.121 \\
NW & 0.149 & $\mathbf{0 . 1 6 9}$ & $\mathbf{0 . 2 3 1}$ & $\mathbf{0 . 1 9 1}$ & $\mathbf{0 . 2 1 5}$ & 0.144 & 0.137 \\
W & 0.151 & 0.143 & $\mathbf{0 . 1 6 4}$ & $\mathbf{0 . 2 1 2}$ & 0.130 & 0.143 & 0.124 \\
SW & 0.137 & 0.139 & 0.150 & $\mathbf{0 . 2 2 7}$ & 0.154 & $\mathbf{0 . 1 8 9}$ & $\mathbf{0 . 1 9 0}$ \\
S & 0.124 & 0.145 & 0.133 & 0.118 & $\mathbf{0 . 2 9 0}$ & $\mathbf{0 . 1 9 6}$ & 0.153 \\
SE & 0.108 & 0.083 & 0.064 & 0.019 & 0.033 & 0.082 \\
\hline
\end{tabular}


TABLE 2c. Twelve-year ensemble mean of the monthly zonal mean azimuthal distribution of the vertical flux of horizontal momentum carried by gravity waves for experiment GWRF1 at launching level in Jul for extratropical latitude bands of $15^{\circ}$. Values exceeding 0.160 are in bold.

\begin{tabular}{cccccccc}
\hline \hline Direction & $90^{\circ}-75^{\circ} \mathrm{N}$ & $75^{\circ}-60^{\circ} \mathrm{N}$ & $60^{\circ}-45^{\circ} \mathrm{N}$ & $45^{\circ}-30^{\circ} \mathrm{N}$ & $30^{\circ}-45^{\circ} \mathrm{S}$ & $45^{\circ}-60^{\circ} \mathrm{S}$ & $60^{\circ}-75^{\circ} \mathrm{S}$ \\
\hline E & 0.120 & 0.100 & 0.101 & 0.089 & 0.123 & 0.121 & 0.121 \\
NE & 0.121 & 0.109 & 0.116 & 0.133 & 0.124 & 0.125 & 0.125 \\
N & 0.130 & 0.159 & 0.148 & $\mathbf{0 . 1 7 3}$ & 0.129 & 0.131 \\
NW & 0.128 & 0.132 & 0.134 & 0.105 & 0.125 & 0.123 & 0.129 \\
W & 0.120 & 0.100 & 0.101 & 0.089 & 0.123 & 0.121 & 0.125 \\
SW & 0.121 & 0.109 & 0.116 & 0.133 & 0.124 & 0.125 & 0.121 \\
S & 0.130 & 0.159 & 0.148 & $\mathbf{0 . 1 7 3}$ & 0.129 & 0.131 & 0.125 \\
SE & 0.128 & 0.132 & 0.134 & 0.105 & 0.125 & 0.123 \\
\hline
\end{tabular}

$60^{\circ} \mathrm{E}$ and $180^{\circ}$ at around $70^{\circ} \mathrm{S}$ corresponds well in the two panels (the peak simulated by the model being slightly eastward compared with the one obtained from the reanalyses). The relatively low magnitude of the discrepancies of the variance distribution between reanalyses and GWRF1 is not expected to produce a significant bias on the middle atmosphere simulation.

Table 2 shows the portion of momentum flux carried by gravity waves along each model azimuthal direction at the launching level and at $70 \mathrm{hPa}$ for the experiment GWRF1. Data are 12-yr ensemble monthly zonal means of $15^{\circ}$ wide latitude bands. At the launching level, mean quasi-isotropy is observed in January and July, although the north-south direction is slightly dominant in the Summer Hemisphere and in the Northern Hemisphere in January. The symmetry in opposing directions is a consequence of the equal bipartition of the momentum flux described in section 2 . At $70 \mathrm{hPa}$, the filtering effect on gravity waves of the prevailing eastward tropospheric flow is obvious and absorption by critical levels reduces the eastward component of the gravity wave momentum flux. The west to southwest directions in the lower stratosphere in July in the $45^{\circ}-60^{\circ} \mathrm{S}$ latitude band agree with anisotropy reported by Vincent et al. (1997) using radiosonde observations made at Macquarie Island (55S). Mean gravity wave anisotropy in the lower stratosphere derived from the SPARC radiosonde initiative is also fairly consistent with results shown in Tables $2 \mathrm{~b}$ and $2 \mathrm{~d}$, showing biases toward the northwest direction in the winter Northern Hemisphere, and toward the southwest direction in the winter Southern Hemisphere at midlatitudes (R. A. Vincent 2001, personal communication).
The ensemble monthly zonal mean azimuthal distribution of horizontal momentum flux carried by gravity waves emerging only from fronts at launching level in January and July is described in Tables $3 a$ and $3 b$. Away from polar regions, the north-south cross-front orientation is mainly preferred, especially in summer. In the winter Northern Hemisphere, a pattern closer to isotropy is obtained north of $45^{\circ} \mathrm{N}$. But the north-south gravity wave propagation direction in the Southern Hemisphere winter tends again to be clearly favored in the model.

In order to illustrate the instantaneous gravity wave distribution when the gravity wave source is modulated by the frontogenesis function of Eq. (2.1) and to compare with observations obtained from aircraft measurements described in Fritts and Nastrom (1992), two snapshots of the total gravity wave wind variance at 180 $\mathrm{hPa}$ are shown in Fig. 5. The upper panel shows the variance at latitude $46^{\circ} \mathrm{N}$ on 8 January at 0000 (model time) of the second year of integration (after the spinup), and the lower panel shows the variance at latitude $46^{\circ} \mathrm{S}$ on 10 July at 1200 (model time) of the same year of integration. The sharp peaks indicate that the threshold of $0.1 \mathrm{~K}^{2}(100 \mathrm{~km})^{-2} \mathrm{~h}^{-1}$ has been reached at these locations, and that frontogenesis is more likely to occur there. Note that the total variance obtained when the threshold is not reached and the variance due the fronts (when the threshold is reached) at $180 \mathrm{hPa}$ are compatible with the numbers given in Fritts and Nastrom (1992). Figure 5 is representative of the overall behavior of the gravity waves at $180 \mathrm{hPa}$ emerging from fronts. The 12-yr model climatology in January at $46^{\circ} \mathrm{N}$ and in July at $46^{\circ} \mathrm{S}$ indicates a mean total variance (at peak locations) of $5.9 \mathrm{~m}^{2} \mathrm{~s}^{-2}$ with a standard deviation of

TABLE 2d. Twelve-year ensemble mean of the monthly zonal mean azimuthal distribution of the vertical flux of horizontal momentum carried by gravity waves for experiment GWRF1 at $70 \mathrm{hPa}$ in Jul for extratropical latitude bands of $15^{\circ}$. Values exceeding 0.160 are in bold.

\begin{tabular}{cccccccc}
\hline \hline Direction & $90^{\circ}-75^{\circ} \mathrm{N}$ & $75^{\circ}-60^{\circ} \mathrm{N}$ & $60^{\circ}-45^{\circ} \mathrm{N}$ & $45^{\circ}-30^{\circ} \mathrm{N}$ & $30^{\circ}-45^{\circ} \mathrm{S}$ & $45^{\circ}-60^{\circ} \mathrm{S}$ & $60^{\circ}-75^{\circ} \mathrm{S}$ \\
\hline E & 0.076 & 0.024 & 0.013 & 0.004 & 0.020 & 0.036 & 0.075 \\
NE & 0.094 & 0.055 & 0.047 & 0.032 & 0.040 & 0.057 & 0.091 \\
N & 0.147 & $\mathbf{0 . 2 5 7}$ & $\mathbf{0 . 2 7 4}$ & $\mathbf{0 . 2 6 0}$ & 0.126 & 0.132 & 0.127 \\
NW & $\mathbf{0 . 1 6 7}$ & $\mathbf{0 . 1 9 9}$ & $\mathbf{0 . 2 1 4}$ & $\mathbf{0 . 1 7 8}$ & $\mathbf{0 . 2 2 3}$ & $\mathbf{0 . 1 8 3}$ & 0.152 \\
W & 0.152 & 0.100 & 0.099 & 0.131 & $\mathbf{0 . 2 2 0}$ & $\mathbf{0 . 1 9 3}$ & 0.159 \\
SW & 0.133 & 0.110 & 0.127 & $\mathbf{0 . 2 4 0}$ & $\mathbf{0 . 2 0 6}$ & $\mathbf{0 . 1 9 2}$ & $\mathbf{0 . 1 6 0}$ \\
S & 0.129 & $\mathbf{0 . 1 9 1}$ & $\mathbf{0 . 1 8 1}$ & 0.142 & 0.131 & 0.145 \\
SE & 0.102 & 0.065 & 0.046 & 0.014 & 0.034 & 0.146 & 0.140 \\
\hline
\end{tabular}


TABLE 3a. Twelve-year ensemble mean of the monthly zonal mean azimuthal distribution of the vertical flux of horizontal momentum carried by gravity waves emerging from fronts for experiment GWRF1 at launching level in Jan for extratropical latitude bands of $15^{\circ}$. Values exceeding 0.160 are in bold.

\begin{tabular}{cccccccc}
\hline \hline Direction & $90^{\circ}-75^{\circ} \mathrm{N}$ & $75^{\circ}-60^{\circ} \mathrm{N}$ & $60^{\circ}-45^{\circ} \mathrm{N}$ & $45^{\circ}-30^{\circ} \mathrm{N}$ & $30^{\circ}-45^{\circ} \mathrm{S}$ & $45^{\circ}-60^{\circ} \mathrm{S}$ & $60^{\circ}-75^{\circ} \mathrm{S}$ \\
\hline E & 0.118 & 0.112 & 0.092 & 0.028 & 0.004 & 0.043 & 0.048 \\
NE & 0.128 & 0.137 & 0.132 & 0.062 & 0.125 & 0.052 & 0.110 \\
N & 0.127 & 0.133 & $\mathbf{0 . 1 6 6}$ & $\mathbf{0 . 2 9 3}$ & $\mathbf{0 . 3 4 7}$ & $\mathbf{0 . 1 9 6}$ & 0.131 \\
NW & 0.127 & 0.118 & 0.110 & 0.118 & 0.024 & $\mathbf{0 . 2 0 9}$ & 0.106 \\
W & 0.118 & 0.112 & 0.092 & 0.028 & 0.004 & 0.043 \\
SW & 0.128 & 0.137 & 0.132 & 0.062 & 0.125 & 0.052 & 0.048 \\
S & 0.127 & 0.133 & $\mathbf{0 . 1 6 6}$ & $\mathbf{0 . 2 9 3}$ & $\mathbf{0 . 3 4 7}$ & $\mathbf{0 . 1 9 6}$ & 0.110 \\
SE & 0.127 & 0.118 & 0.110 & 0.118 & 0.024 & $\mathbf{0 . 2 3 6}$ & 0.125 \\
\hline
\end{tabular}

$1.8 \mathrm{~m}^{2} \mathrm{~s}^{-2}$. This mean total variance is close to what is shown by Fritts and Nastrom (1992) in their Fig. 15, although they seem to observe more variability than in the present simulation. This apparent lack of variability in the simulation is easily understandable considering that for the sake of simplicity, a constant total variance of $4 \mathrm{~m}^{2} \mathrm{~s}^{-2}$ has been imposed at the source level for frontal gravity waves. Of course, the values given by Fritts and Nastrom (1992) may not only describe gravity wave motion, and the atmospheric phenomena at the origin of this variance may not necessarily transport momentum as efficiently as pure gravity waves, whereas the model parameterization does.

Figure 5 depicts another interesting feature of the gravity waves reaching the model lower stratosphere. The total variance values of the gravity wave emerging from nonfrontal zones at $180 \mathrm{hPa}$ are approximately of the same intensity as at the launching level, whereas the variance at $180 \mathrm{hPa}$ of the gravity waves emerging from fronts is almost twice its launching level value. A possible physical mechanism that could explain the variance enhancement for the gravity waves emerging from fronts goes as follows: Since fronts are, in a semigeostrophic-type argument, associated with tropospheric winds that are generally oriented in the alongfront direction, and since the gravity waves emerging from fronts are parameterized in such a way that their propagation direction is perpendicular to the alongfront direction, the mean impact of critical level filtering in the troposphere is thus reduced to favor a deeper penetration of gravity waves emerging from fronts in the stratosphere. Evidence that the simulated tropospheric wind above the launching level is indeed oriented in the alongfront direction is presented in Fig. 6, which depicts the wind orientation with respect to pressure and the alongfront direction at the launching level for the frontal zones shown in Fig. 5.

\section{b. Gravity wave momentum flux and induced force}

The space and time structure of the vertical flux of horizontal momentum (hereafter, momentum flux) carried by gravity waves reaching the middle atmosphere is modulated by at least two important factors: the strength and variability of the sources, and the char- acteristics of the medium in which the waves are propagating. The 12-yr ensemble and zonal mean of the net zonal momentum flux, parameterized by the Hines scheme, from the GWRF1 simulation is shown in Fig. 7 for January and July (upper panels). In the troposphere and winter stratosphere the net zonal flux is negative, as expected from wave filtering due to the generally positive zonal winds. Note that there is a hemispheric asymmetry, with the magnitude of the net zonal flux substantially smaller during both northern and southern summers than the respective winters. This asymmetry (also seen in the troposphere) is consistent with the smaller gravity wave variance in summer at the launching height (see Fig. 2). Moreover, a stronger net negative extratropical momentum flux reaches the higher stratosphere in southern winters than in northern winters. This is due to enhanced critical level filtering of eastwardpropagating waves by stronger eastward winds in the lower stratosphere during the southern winters as compared with northern winters.

The middle and lower panels of Fig. 7 estimate the changes in the net zonal momentum flux within the range of the sensitivity tests performed. The difference between UNI1 and GWRF1 shows that frontal sources, as parameterized in the present work, tend to produce a significant increase in westward momentum flux reaching the lower stratosphere in winter. In the lower stratosphere (around $100 \mathrm{hPa}$ ) in winter, the flux of westward net momentum is more than doubled at $60^{\circ}(\mathrm{N}$ and $\mathrm{S}$ ) when fronts are parameterized as gravity wave sources. Such an increase in the magnitude of the momentum flux is consistent with the larger gravity wave variance at the launching level in GWRF1 with respect to UNI1. The mean zonal net momentum flux of the summer hemispheres in January and July is almost unaltered by the frontal source parameterization as can be expected from the fact that the selected threshold for the frontogenesis function is more rarely reached in summer. The average gravity wave variance at the launching level in GWRF1 is indeed close to the constant value specified in UNI1.

The difference between UNI2 and GWRF1 (lower panels of Fig. 7) shows that the mean net zonal momentum flux of the UNI2 simulation resembles more the one simulated by the GWRF1 experiment. Given 
TABLE 3b. Twelve-year ensemble mean of the monthly zonal mean azimuthal distribution of the vertical flux of horizontal momentum carried by gravity waves emerging from fronts for experiment GWRF1 at launching level in Jul for extratropical latitude bands of $15^{\circ}$. Values exceeding 0.160 are in bold.

\begin{tabular}{cccccccc}
\hline \hline Direction & $90^{\circ}-75^{\circ} \mathrm{N}$ & $75^{\circ}-60^{\circ} \mathrm{N}$ & $60^{\circ}-45^{\circ} \mathrm{N}$ & $45^{\circ}-30^{\circ} \mathrm{N}$ & $30^{\circ}-45^{\circ} \mathrm{S}$ & $45^{\circ}-60^{\circ} \mathrm{S}$ & $60^{\circ}-75^{\circ} \mathrm{S}$ \\
\hline E & 0.096 & 0.077 & 0.037 & 0.017 & 0.019 & 0.073 & 0.068 \\
NE & 0.127 & 0.130 & 0.130 & 0.071 & 0.149 & 0.104 & 0.093 \\
N & $\mathbf{0 . 1 6 1}$ & $\mathbf{0 . 1 6 8}$ & $\mathbf{0 . 2 4 6}$ & $\mathbf{0 . 3 0 4}$ & $\mathbf{0 . 2 6 4}$ & $\mathbf{0 . 1 7 5}$ \\
NW & 0.116 & 0.126 & 0.087 & 0.108 & 0.068 & 0.148 & 0.115 \\
W & 0.096 & 0.077 & 0.037 & 0.017 & 0.019 & 0.073 & 0.134 \\
SW & 0.127 & 0.130 & 0.130 & 0.071 & 0.149 & 0.104 & 0.068 \\
S & $\mathbf{0 . 1 6 1}$ & $\mathbf{0 . 1 6 8}$ & $\mathbf{0 . 2 4 6}$ & $\mathbf{0 . 3 0 4}$ & $\mathbf{0 . 2 6 4}$ & $\mathbf{0 . 1 7 5}$ & 0.135 \\
SE & 0.116 & 0.126 & 0.087 & 0.108 & 0.068 & 0.148 \\
\hline
\end{tabular}

the imposed stronger forcing in summer in UNI2 with respect to GWRF1, the flux reaching the summer lower stratosphere in the UNI2 simulation is expected to be larger, as is shown in Fig. 7. Both northern and southern winters are instead characterized by a decrease in net westward zonal momentum flux in the stratosphere, poleward of $45^{\circ}$ of latitude, in the UNI2 with respect

Instantaneous GW var. at $180 \mathrm{hPa}$ and $46 \mathrm{~N}$

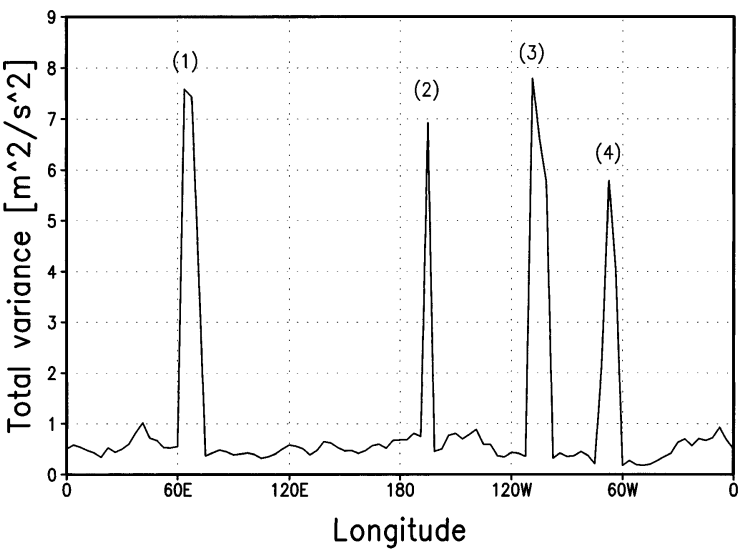

Instantaneous $\mathrm{GW}$ var. at $180 \mathrm{hPa}$ and $46 \mathrm{~S}$

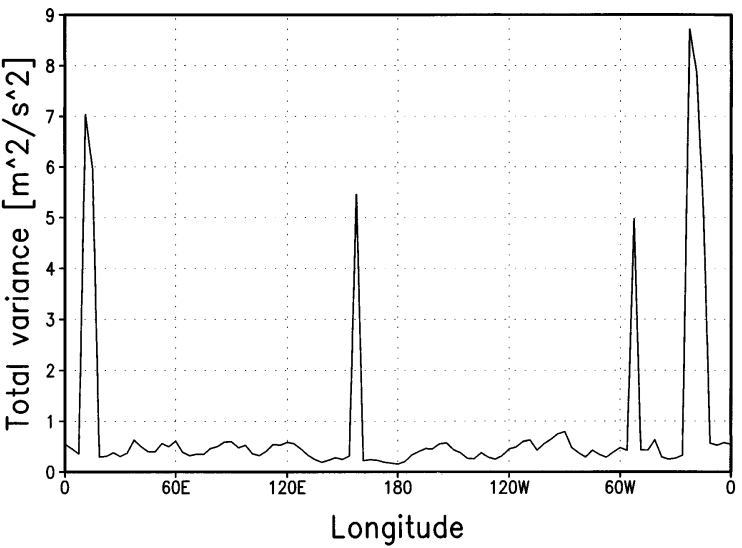

FIG. 5. (upper panel) Snapshot of the total gravity wave wind variance $\left(\mathrm{m}^{2} \mathrm{~s}^{-2}\right)$ at $180 \mathrm{hPa}$ and $46^{\circ} \mathrm{N}$ on $8 \mathrm{Jan}$ at 0000 (model time) of the second year of integration for GWRF1. The fronts are numbered for reference in Fig. 6. (lower panel) Snapshot of the total gravity wave wind variance $\left(\mathrm{m}^{2} \mathrm{~s}^{-2}\right)$ at $180 \mathrm{hPa}$ and $46^{\circ} \mathrm{S}$ on $10 \mathrm{Jul}$ at 1200 (model time) of the second year of integration for GWRF1. to the GWRF1 simulation, even if the respective gravity wave variances at launching level are comparable at these latitudes. Such a difference is most clear in the southern winter (July), where the UNI2 momentum flux is reduced by about $30 \%$ as compared to the GWRF1 simulation. The 12-yr average propagation conditions (background wind and temperature) in the troposphere being almost identical in simulations GWRF1 and UNI2, this difference in the average net zonal momentum flux in the stratosphere is thought to be due to the particular tropospheric background flow conditions in conjunction with the specified characteristics of the gravity waves when they are emitted from frontogenesis zones in simulation GWRF1. As is explained at the end of section $4 \mathrm{a}$, gravity waves emerging from fronts are able to penetrate more easily in the stratosphere than gravity waves with an isotropic spectrum. When these waves reach the stratosphere, the dominant eastward winds filter out the eastward momentum flux carried by these gravity waves, consistently with Fig. 7. The average anisotropic azimuthal distribution of horizontal momentum flux carried by gravity waves emerging from fronts at launching level described in Tables $3 \mathrm{a}$ and $3 \mathrm{~b}$ appears therefore not to be strong enough to perturb the overall scenario described above. The zonal mean westward momentum flux at launching level around $60^{\circ}$ of latitude in winter in simulation GWRF1 has indeed been found to be reduced by only $3 \%$ as compared with simulation UNI2 (not shown).

This selective filtering effect by the background tropospheric flow implies that the role of fronts in generating an increased asymmetric net momentum flux carried by gravity waves might not be accurately simulated when a constant, uniform, and isotropic gravity wave forcing is employed.

The upper panels of Fig. 8 depict the 12-yr ensemble mean of the zonally averaged zonal force per unit mass obtained from the Hines parameterization for the GWRF1 simulation in January and July. Note that when it will be later referred to the gravity wave-induced force per unit mass, it is meant the one obtained from the Hines parameterization only, not the total one that also includes the contribution from the orographic gravity wave parameterization. The difference plots (UNI1GWRF1 and UNI2-GWRF1) of the gravity wave-in- 


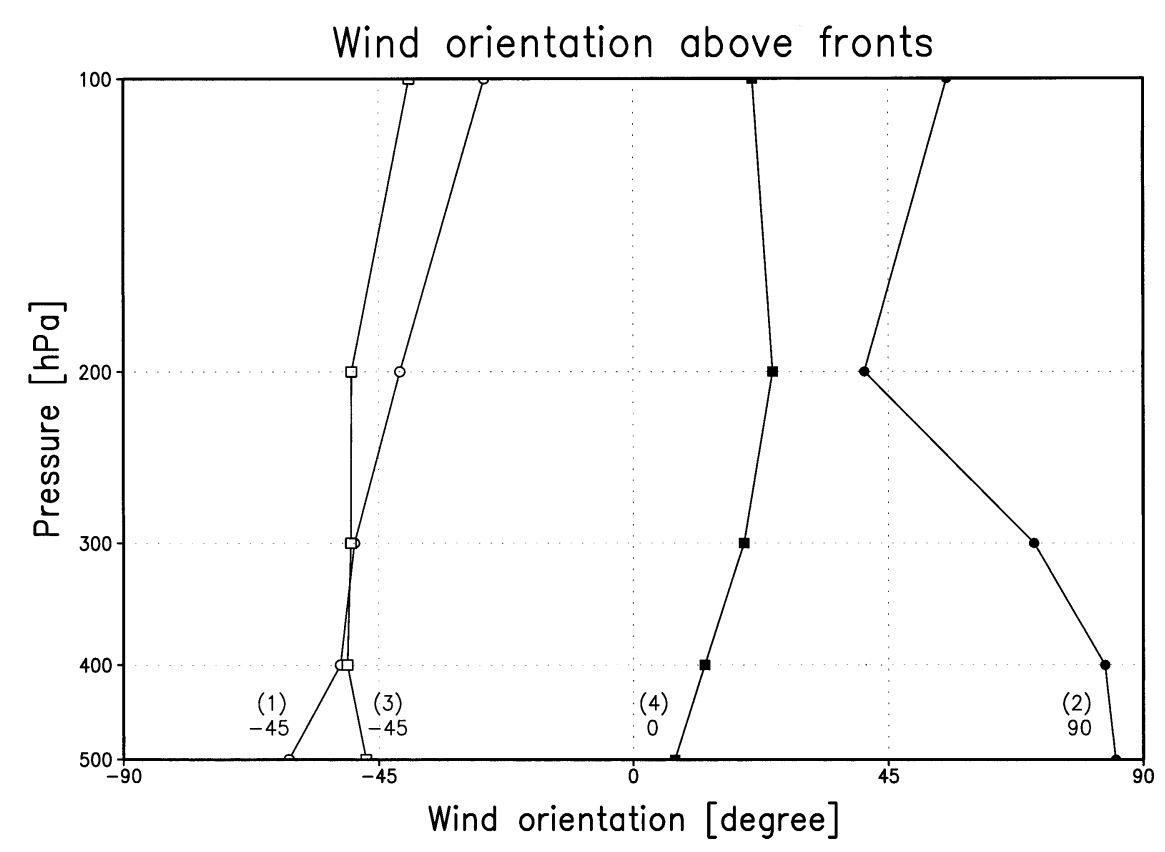

FIG. 6. Orientation of the wind as a function of pressure at specific locations corresponding to diagnosed fronts at $46^{\circ} \mathrm{N}$ on $8 \mathrm{Jan}$ at 0000 (model time) in GWRF1. The numbers in parentheses near the curves refer to the locations labeled in Fig. 5, and the numbers just below those in parentheses indicate the alongfront directions in degrees at launching level derived from the gravity wave propagation directions. Here $0^{\circ}$ corresponds to east, $90^{\circ}$ to north, $-90^{\circ}$ to south, and $180^{\circ}$ to west. It can be seen that the tropospheric wind above the launching level generally points in the alongfront direction.

duced force per unit mass are, respectively, shown in the middle and lower panels.

In the summer hemispheres, the mean zonal gravity wave-induced force per unit mass in simulations GWRF1 and UNI1 is comparable, while in simulation UNI2 it is somewhat stronger (with respect to both GWRF1 and UNI1). The UNI2 gravity wave-induced force per unit mass also tends to be less confined to the upper mesosphere. These results are consistent with the previously shown results for the net zonal momentum fluxes and for the gravity wave variances.

In winter, the mean zonal gravity wave-induced force per unit mass tends to act lower in the mesosphere in simulation GWRF1 with respect to both the UNI1 and UNI2 simulations. As expected from the respective differences in the net zonal momentum fluxes, the difference (with respect to GWRF1) in the vertical structure of the zonal gravity wave-induced force per unit mass is much more pronounced for UNI1 than UNI2.

\section{Monthly and zonal mean winds and temperatures}

\section{a. GWRF1 simulation versus observations}

The 12-yr ensemble mean of the zonally averaged zonal wind in January and July from the GWRF1 simulation is shown in Fig. 9. The 15-yr ensemble mean from the National Center for Environmental Prediction
(NCEP) and Climate Prediction Center (Randel 1992, updated) for pressures above $1 \mathrm{hPa}$ and the COSPAR International Reference Atmosphere-1986 (CIRA86, see Fleming et al. 1990) data for pressures below $1 \mathrm{hPa}$ (thereafter, the NCEP and CIRA86 data will be referred to as "observations") are also shown in Fig. 9 for comparison.

The general features of the observations are reproduced to a relatively good accuracy by the GWRF1 simulation, in both January and July. Both the strength and the structure of the simulated winds in the extratropical middle atmosphere are comparable to the observations. In particular, for both months, note the equatorial tilt of the winter eastward jet, with largest winds in the polar lower stratosphere and in the mesosphere between $30^{\circ}$ and $45^{\circ} \mathrm{N}$, and the poleward tilt of the summer westward jet, stretching from the subtropics in the stratosphere to the middle high latitudes in the upper mesosphere. The discrepancies in the wind strength more pronounced in the mesosphere could be improved in a number of ways, including, for instance, slight changes in the gravity wave forcing. However, the observations themselves may be biased, this being a known case, for instance, in the tropical middle atmosphere (see Randel 1992; Fleming et al. 1990).

In July, the simulated tilt with height toward the equator of the winter middle atmospheric jet core can be due in good part to the gravity wave-induced force per unit 

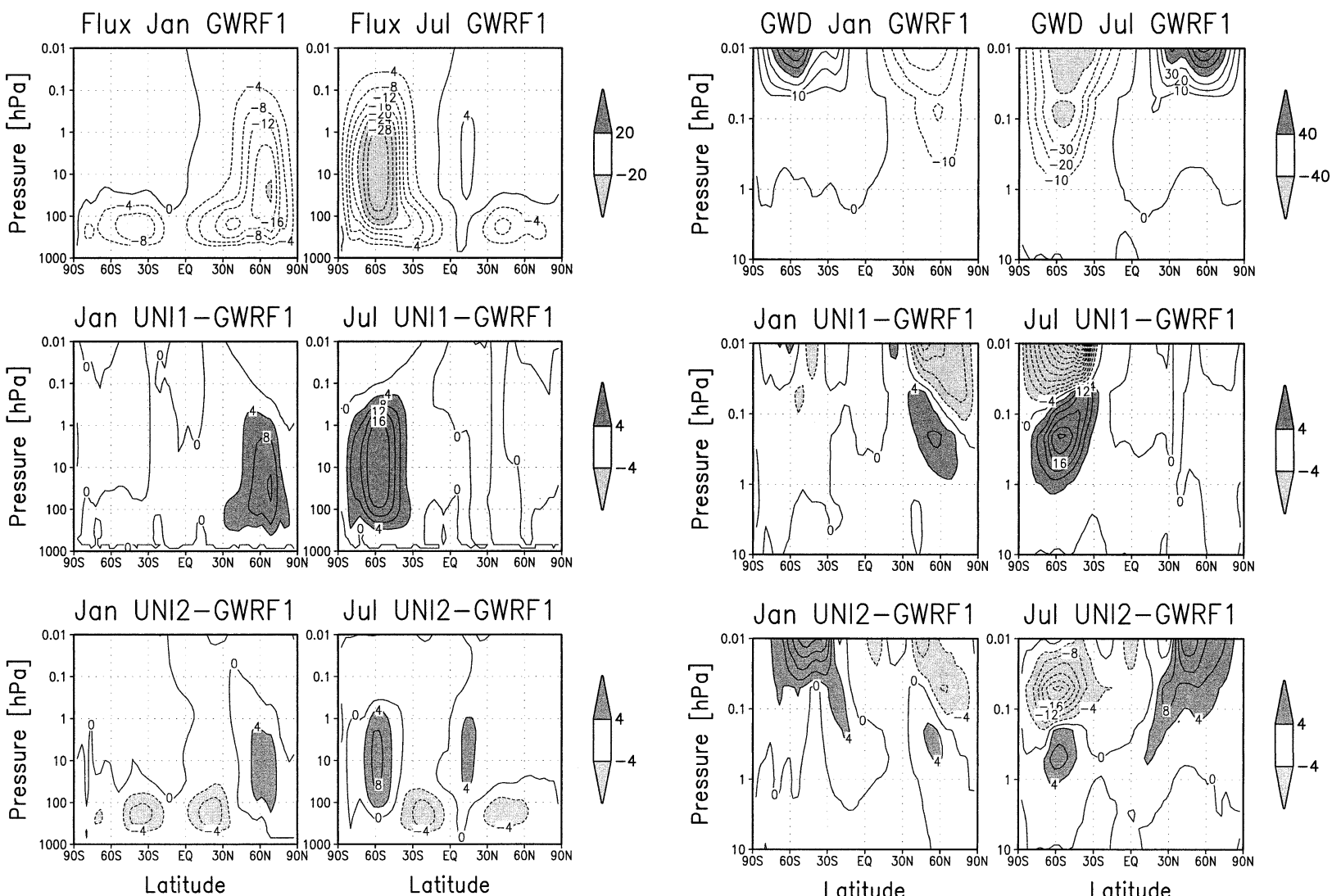

FIG. 7. Latitude-height cross section of the 12-yr ensemble mean of the zonal mean net vertical flux of zonal momentum $\left(10^{-4} \mathrm{~Pa}\right)$ carried by gravity waves parameterized using the Hines scheme for (upper-left panel) Jan and (upper-right panel) Jul for the GWRF1 simulation. (middle panels) Difference between the UNI1 and GWRF1 simulations for (left) Jan and (right) Jul. (lower panels) Difference between the UNI2 and GWRF1 simulations for (left) Jan and (right) Jul. The contour interval is $4 \times 10^{-4} \mathrm{~Pa}$.

mass distribution implied by the presence of the frontal source parameterization, as is shown by comparing with the sensitivity tests (see below).

The stratospheric temperature is of particular interest given that middle atmospheric models tend, in general, to produce a strong cold bias over the winter poles when the gravity wave forcing is too weak. Such a polar bias is indeed sensitive to the level of gravity wave forcing that is parameterized in low-resolution models. Concerning an earlier evaluation of the sensitivity of the middle atmosphere circulation as simulated by the MAECHAM4 model to the forcing used in the Hines parameterization, see Manzini and McFarlane (1998).

In the case of the GWRF1 simulation, Fig. 10 shows that the model mean temperature bias is below $4 \mathrm{~K}$ from 100 to $10 \mathrm{hPa}$ for all the months of the year at $87^{\circ} \mathrm{N}$ and $87^{\circ} \mathrm{S}$. Stronger cold biases occur at pressures between 10 and $1 \mathrm{hPa}$ in northern and southern summers, where they can reach 9-10 $\mathrm{K}$ in the model upper stratosphere. At $87^{\circ} \mathrm{S}$ in April-May, a warm bias of about 6 $\mathrm{K}$ is observed between 10 and $1 \mathrm{hPa}$. As it stands, the

FIG. 8. Latitude-height cross section of the 12-yr ensemble mean of the zonal mean net zonal gravity wave-induced force per unit mass $\left(\mathrm{m} \mathrm{s}^{-1} \mathrm{day}^{-1}\right)$ parameterized using the Hines scheme for (upper-left panel) Jan and (upper-right panel) Jul for the GWRF1 simulation. (middle panels) Difference between the UNI1 and GWRF1 simulations for (left) Jan and (right) Jul. (lower panels) Difference between the UNI2 and GWRF1 simulations for (left) Jan and (right) Jul. The mean zonal-induced force per unit mass below $10 \mathrm{hPa}$ being essentially zero, only middle stratospheric and mesospheric values are shown. The contour intervals are $10 \mathrm{~m} \mathrm{~s}^{-1} \mathrm{day}^{-1}$ for the upper panels, and $4 \mathrm{~m} \mathrm{~s}^{-1}$ day $^{-1}$ for the middle and lower panels.

GWRF1 simulation seems to be too far from radiative equilibrium (Fels et al. 1980; Fels 1985) and dynamical cooling in the model summer upper stratosphere by breaking waves (resolved or parameterized) seems to be too strong. This is also reflected in Fig. 9 where the mean stratospheric winter zonal wind maxima of the GWRF1 simulation appear to be too weak. The specified stratospheric ozone concentrations used in the simulation might also be responsible for parts of the polar temperature biases in the model stratosphere and mesosphere.

\section{b. Sensitivity tests: GWRF1 versus UNI1 and UNI2}

The 12-yr ensemble mean of the January and July zonal mean zonal winds from the UNI1 and UNI2 simulation are both shown in Fig. 11. The most remarkable 

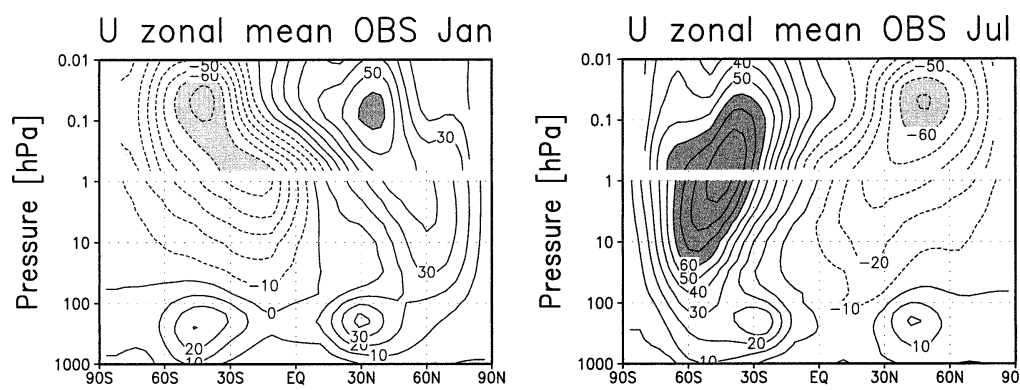

U zonal mean GWRF1 Jan
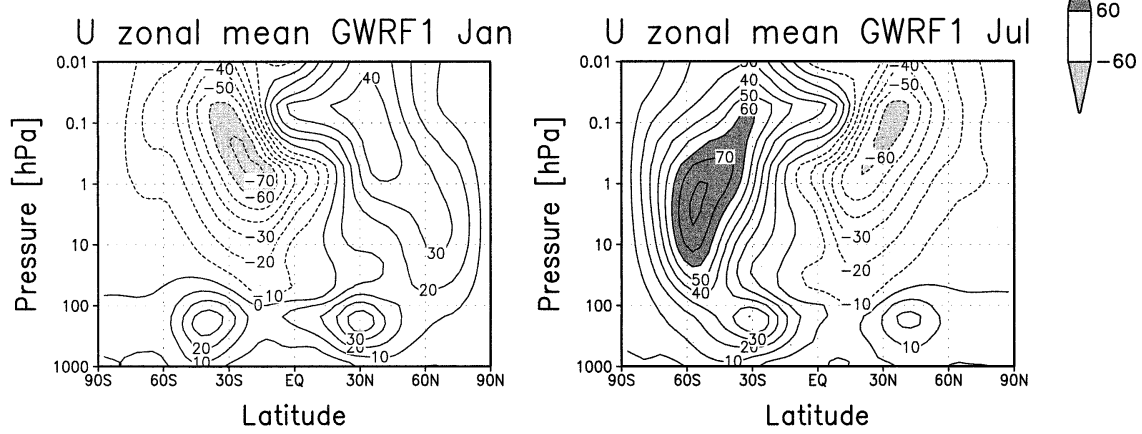

FIG. 9. Latitude-height cross section of the zonal mean zonal wind velocity $\left(\mathrm{m} \mathrm{s}^{-1}\right)$ in (left panels) Jan and (right panels) Jul. (upper panels) Composite of 15-yr ensemble mean of NCEP data for pressures greater than $1 \mathrm{hPa}$ and CIRA86 data for pressures lower than $1 \mathrm{hPa}$. (lower panels) Twelve-year ensemble mean from the GWRF1 simulation. The contour interval is $10 \mathrm{~m}$ $\mathrm{s}^{-1}$.

$T$ zonal mean OBS $87 \mathrm{~N}$

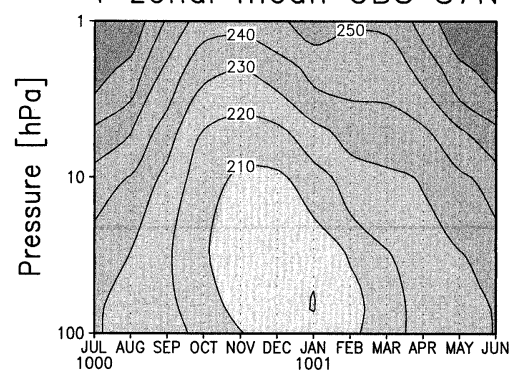

T GWRF1-OBS $87 \mathrm{~N}$

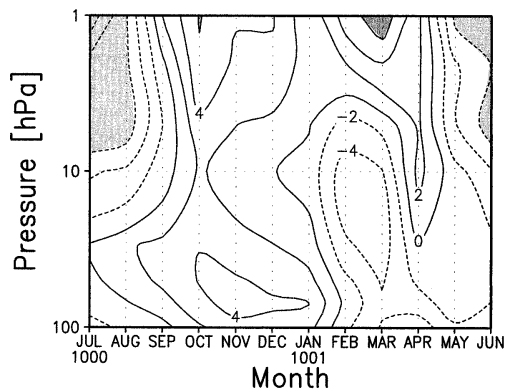

$T$ zonal mean OBS 875

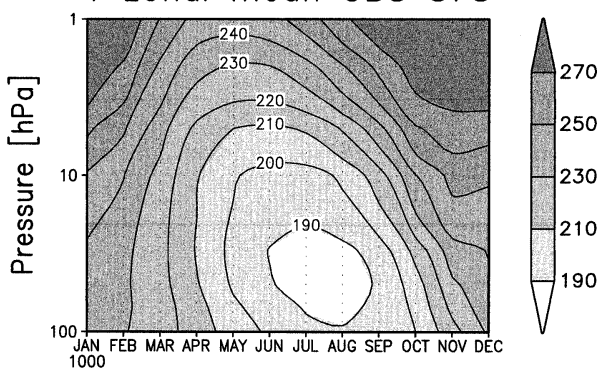

T GWRF1-OBS 87S

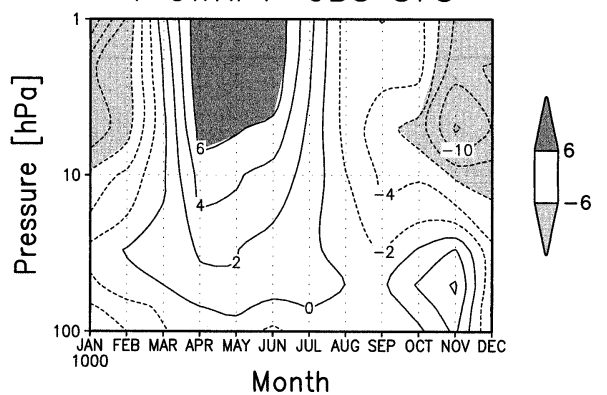

FIG. 10. Time-height cross section of the monthly zonal mean temperature (K) at (upper-left panel) $87^{\circ} \mathrm{N}$ and (upper-right panel) $87^{\circ} \mathrm{S}$ for the 15 -yr ensemble mean NCEP data. (lower panels) Difference between the 12-yr ensemble mean of the GWRF1 simulation and the 15-yr ensemble mean NCEP data. The contour intervals are $10 \mathrm{~K}$ for the upper panels, and $2 \mathrm{~K}$ for the lower panels. 

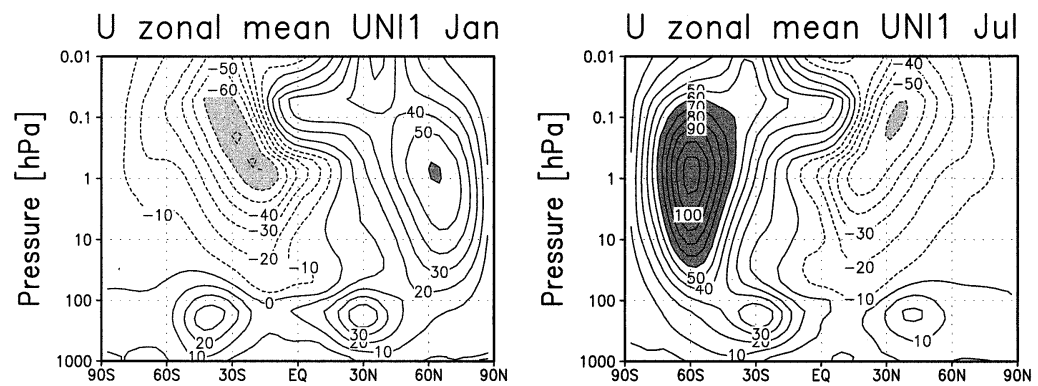

U zonal mean UNI2 Jan
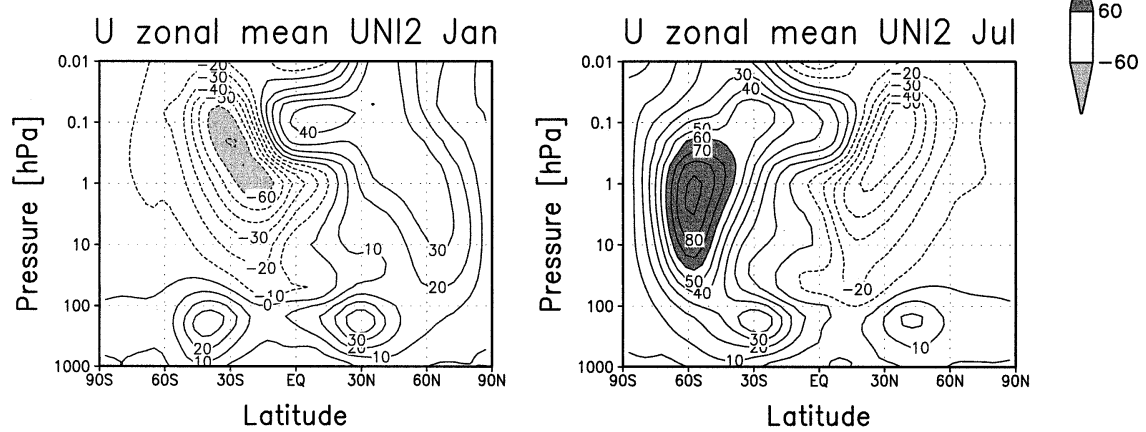

FIG. 11. Latitude-height cross section of the 12-yr ensemble mean of the zonal mean wind velocity $\left(\mathrm{m} \mathrm{s}^{-1}\right.$ ) in (left panels) Jan and (right panels) Jul. (upper panels) UNI1 simulation. (lower panels) UNI2 simulation. The contour interval is $10 \mathrm{~m} \mathrm{~s}^{-1}$.
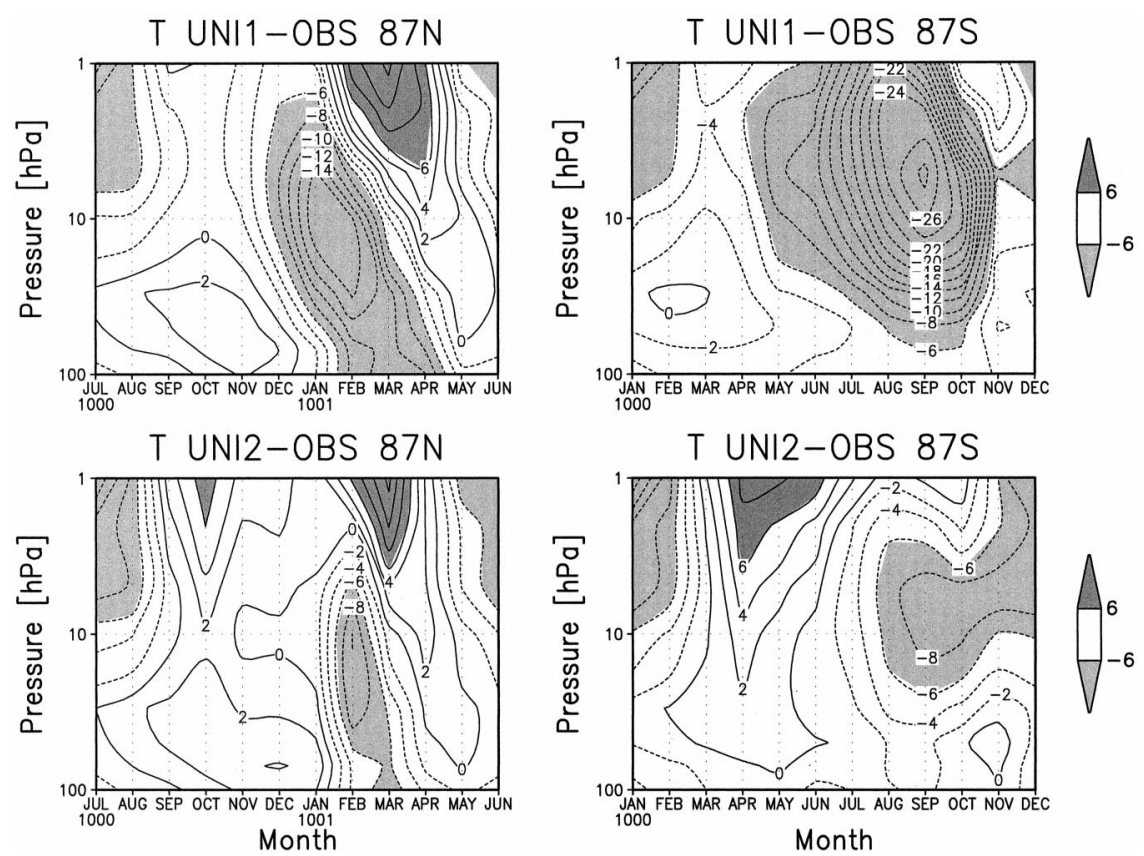

FIG. 12. Time-height cross section of the monthly zonal mean temperature difference $(\mathrm{K})$ at (left panels) $87^{\circ} \mathrm{N}$ and (right panels) $87^{\circ} \mathrm{S}$ between the (upper panels) 12 -yr ensemble mean UNI1 simulation and the 15-yr ensemble mean NCEP data, and between the (lower panels) 12 yr ensemble mean UNI2 simulation and the 15-yr ensemble mean NCEP data. The contour interval is $2 \mathrm{~K}$. 
differences among the simulations are found in the extratropical winter middle atmosphere.

In both January and July, the UNI1 polar night stratospheric jet is substantially stronger and confined at high latitudes also in the upper stratosphere and mesosphere (i.e., no equatorward tilt with height), with respect to GWRF1. In particular, in January, the UNI1 core of the middle atmospheric jet is located north of $60^{\circ} \mathrm{N}$ and near the stratopause, whereas it is higher, somewhat weaker, and closer to $30^{\circ} \mathrm{N}$ in GWRF1 (the latter more in accord with the observed location). In July, the middle atmospheric jet in the Southern Hemisphere of the UNI1 simulation is stronger than the one simulated from GWRF1 by $20-30 \mathrm{~m} \mathrm{~s}^{-1}$. Although the simulated zonal winds depend not only on the Hines gravity wave tendency, but also from the resolved wave driving as well as other parameterizations (among which the major role is played by the orographic gravity wave scheme) and feedbacks between the zonal flow and wave propagation, the changes in the average zonal winds in both January and July winter hemispheres are consistent with the stronger gravity wave forcing caused by frontal activity in simulation GWRF1.

In the summer hemispheres, the UNI1 and GWRF1 average zonal winds are quite comparable, as it can be expected by the similar gravity wave tendency described earlier. In summer, the zonal winds are much more likely to be dominated by the contribution from the Hines parameterization only.

In general, the strength of the UNI2 and GWRF1 zonal winds is more comparable (with respect to the difference between UNI1 and GWRF1), although the UNI2 winds are substantially weaker in the extratropical winter mesosphere, in both January and July. In particular, UNI2 Iacks the equatorward tilt with height in July in the southern hemisphere. The difficulty to obtain this tilt with a constant forcing of the gravity wave variance was already noted in Manzini and McFarlane (1998). The changes between UNI1 and UNI2 are consistent with the results reported in Manzini and McFarlane (1998). The tilt of the winter jet in July is therefore quite likely due to the distribution of gravity wave tendency when frontal activity is included in the source spectrum. Concerning the summer hemisphere in July, it is noted that GWRF1 and UNI1 are closer to the observations, suggesting that the constant forcing of UNI2 is less adequate in this case.

In summary, the seasonal variation of the gravity wave forcing at source level introduced in simulation GWRF1 is clearly helpful in reproducing a more realistic intensity and structure of the zonal mean zonal winds.

Figure 12 depicts the time-height cross section of the 12 -yr ensemble mean difference of the monthly zonal mean temperature between the UNI1 (UNI2) simulation and the observations in the stratosphere at $87^{\circ} \mathrm{S}$ and $87^{\circ} \mathrm{N}$.

In the case of UNI 1 at $87^{\circ} \mathrm{N}$, the mean cold bias reaches $14 \mathrm{~K}$ at $10 \mathrm{hPa}$ in January and propagates downward to $100 \mathrm{hPa}$ with a slightly weaker intensity until late winter and early spring. Above it, a warm bias appears that reaches 10-12 K in February and March. From May to December the average temperature bias is fairly similar in simulations GWRF1 and UNI1, in particular the upper-stratospheric cold bias in summer remains almost the same.

In the case of UNI1 at $87^{\circ} \mathrm{S}$, a large winter and spring mean cold bias that reaches $28 \mathrm{~K}$ near the $10-\mathrm{hPa}$ level is found. Therefore, the sensitivity of the Southern Hemispheric winter pole temperature to the parameterized gravity wave forcing by fronts appear to be remarkable. As for the northern polar temperature, the model summer stratospheric polar temperature is almost unaffected by the inclusion of fronts in the gravity wave forcing, as is seen by comparing Fig. 10 (lower right panel) and Fig. 12 (upper right panel) in January.

The mean polar temperature bias of the UNI2 simulation mainly resembles the one of GWRF1. Interesting differences however are seen. Namely, an 8-10 K cold bias in February below the $7-\mathrm{hPa}$ level at $87^{\circ} \mathrm{N}$ present in simulation UNI2 is attenuated to $\sim 4 \mathrm{~K}$ in simulation GWRF1. Moreover, in simulation UNI2, a cold bias of $8 \mathrm{~K}$ at around and above the $10-\mathrm{hPa}$ level at $87^{\circ} \mathrm{S}$ extends from August to February. As mentioned earlier, a similar cold bias is present in simulation GWRF1, but extends from October to February, with a somewhat stronger intensity in November. Although it is thought that this cold bias might be due in part the specified ozone distribution, the gravity wave parameterization has obviously some impact on it.

\section{Summary and conclusions}

This study addresses the question of the parameterization of gravity wave sources in general circulation models of the middle atmosphere by proposing a simple method aimed at representing gravity waves emerging from frontal zones. Based on an evaluation of the frontogenesis function near $600 \mathrm{hPa}$ at each grid point and time step, which is found to be a good indicator of fronts at relatively low resolution in the model middle troposphere, gravity waves with total wind variance of 4 $\mathrm{m}^{2} \mathrm{~s}^{-2}$ are launched in the two cross-front directions with equally bipartioned momentum flux when a minimal threshold of $0.1 \mathrm{~K}^{2}(100 \mathrm{~km})^{-2} \mathrm{~h}^{-1}$ is reached. In the alternative case for which the frontogenesis function does not reach the selected threshold, an isotropic gravity wave spectrum with total wind variance of $0.64 \mathrm{~m}^{2}$ $\mathrm{s}^{-2}$ representing other possible gravity wave sources is imposed at the launching level.

This parameterization based on resolved deformation and convergence fields in the model middle troposphere leads to a gravity wave source intensity that has local maxima at known storm track locations. Moreover, a seasonal modulation of the monthly and zonal mean total gravity wave wind variance at the model launching level is observed with minimum in summer, especially in the Northern Hemisphere. Instantaneous values of the 
total gravity wave wind variance entering the lower stratosphere seem to mimic relatively well the wind variances calculated from measurements made by instruments installed on commercial aircrafts.

In order to evaluate the specific role of the gravity waves emerging from frontal sources in the modeling context of the above-mentioned parameterization, one resolution and two sensitivity tests have been performed. The increase of the model triangular truncation from T30 to T42 leads to a slight global increase in the mean total gravity wave wind variance in the extratropics at launching level. The mean middle atmosphere winds and temperatures at T30 and T42 remain, however, the same.

In the first sensitivity test, the effects on the model middle atmosphere of gravity waves emerging from fronts have been suppressed by imposing a uniform and constant total gravity wave wind variance of $0.64 \mathrm{~m}^{2}$ $\mathrm{s}^{-2}$ at the launching level at each grid point and time step. In summer, the monthly and zonal mean vertical flux of zonal momentum carried by gravity waves reaching the middle atmosphere is almost unchanged when gravity waves from fronts are suppressed, but the winter values are more than doubled when the effects of gravity waves from fronts are included.

In the second sensitivity test, a uniform and constant gravity wave wind variance of $1 \mathrm{~m}^{2} \mathrm{~s}^{-2}$ is specified at the launching level. This variance is very close to the monthly and zonal mean extratropical variance observed in the simulation that included enhanced parameterized gravity waves activity and for which fronts were acting as gravity wave sources. It turned out that even though the mean strength of the gravity wave forcing and the mean characteristics of the propagating medium in the two experiments are essentially the same in winter, the mean negative vertical flux of zonal momentum reaching the middle atmosphere is found to be more important when gravity waves from fronts are present, especially at $60^{\circ} \mathrm{S}$ in July. This is essentially caused by the fact that tropospheric filtering effects by critical levels are reduced when gravity waves emerge from frontal zones since the gravity wave propagation directions and the wind direction are almost perpendicular.

The mean mesospheric zonal gravity wave-induced force per unit mass of the two sensitivity experiments tends to be higher near the model top in winter than in the GWRF1 simulation. On the other hand, the mean winter zonal-induced force per unit mass of the GWRF1 simulation acts lower in the mesosphere than for the sensitivity tests, in accordance with the fact that the initial amplitude of the parameterized gravity waves emerging from frontal zones is greater than the selected constant amplitude in the sensitivity tests, and despite the relatively small amplitude of waves emerging from nonfrontal zones.

The modulation from the frontal parameterization of gravity wave wind variance at launching level in experiment GWRF1 is found to be helpful in simulating a more realistic zonal mean middle atmospheric jet in the Northern Hemisphere in July. During that month, a simulation with a gravity wave forcing that is uniform at launching level suffers from a too strong middle atmospheric jet in the Southern Hemisphere (simulation UNI1) or a slightly too weak jet in the Northern Hemisphere (simulation UNI2). Moreover, the observed equatorward tilt of the mean zonal middle atmospheric jet in the Southern Hemisphere in July is more pronounced and closer to observations in GWRF1 than in UNI1 and UNI2.

The stratospheric mean polar cold bias in the Southern Hemisphere in winter obtained in the absence of gravity waves emerging from frontal zones can reach $25-30 \mathrm{~K}$ near $5 \mathrm{hPa}$ (simulation UNI1), but is reduced to $2-4 \mathrm{~K}$ when these gravity waves are included. Among the four simulations performed for this study, the temperature biases at the poles are found to be minimal when part of the parameterized gravity wave activity is modulated by frontogenesis.

As gravity waves are a major mesospheric forcing that can greatly impact on the stratospheric circulation, establishing a source parameterization based on our dynamical knowledge of their generation mechanisms should help in obtaining realistic simulations of the middle atmosphere. In the MAECHAM4 model, the medium in which parameterized gravity waves are propagating is surely very important in determining the broad characteristics of these waves that will reach the middle atmosphere, but this study shows that a gravity wave source spectrum that is related, even though somewhat crudely, to dynamical mechanisms leading to gravity wave emission can improve simulations of the middle atmosphere in terms of zonal mean fields. Other issues that have not been addressed here concern the impact of the seasonal and geographical variations introduced by the modulation from the frontal parameterization of gravity wave characteristics on the nonzonal circulation of the middle atmosphere. For instance, if the structure and strength of planetary waves and consequently the interannual variability of the winter circulation is changed between GWRF1 and UNI1 or UNI2. Such questions will be addressed in a following work.

Improvements to the current approach include a more detailed specification of the gravity wave parameters at the launching height. In particular, note that the results of simulation GWRF1 were obtained assuming a source that emits gravity waves symmetrically in the two crossfront directions. This lead to an increase of gravity wave westward momentum flux in the winter stratosphere as compared with simulations UNI1 and UNI2 (Fig. 7). Griffiths and Reeder (1996) report that a slight asymmetry of the gravity wave emission in the two crossfront directions is observed in the absence of vertical shear of the cross-front basic wind, although stronger asymmetry is observed when cross-front basic wind shear is present. More theoretical, observational and numerical investigations are needed to really understand 
the characteristics of gravity waves emerging from fronts in order to establish a parameterization that is more sophisticated than the one employed in this work. In addition, convective and jet stream gravity wave excitation are mechanisms that would also need to be taken into account in order to get a more complete picture of the impact of modulating the gravity wave emission by relevant dynamical phenomena in middle and upperatmospheric general circulation models.

Acknowledgments. The authors are thankful to $\mathrm{L}$. Bengtsson for having encouraged the initiation of this work. They also thank Ms. Joumana Ghosn for her judicious advice, and the anonymous reviewers for constructive comments. Part of this work was supported by the IGWOC project of the European Commission Environment and Climate Research Programme (Contract ENV4-CT97-0486).

\section{REFERENCES}

Alexander, M. J., 1998: Interpretation of observed climatological patterns in stratospheric gravity wave variance. J. Geophys. Res., 103, 8627-8640.

Allen, S. J., and R. A. Vincent, 1995: Gravity wave activity in the lower atmosphere: Seasonal and latitudinal variations. J. Geophys. Res., 100, 1327-1350.

Blackmon, M. L., 1976: A climatological spectral study of the 500$\mathrm{mb}$ geopotential height of the northern hemisphere. J. Atmos. Sci., 33, 1607-1623.

_- Y.-H. Lee, and J. M. Wallace, 1984: Horizontal structure of $500-\mathrm{mb}$ height fluctuations with long, intermediate, and short timescales. J. Atmos. Sci., 41, 961-979.

Eckermann, S. D., and R. A. Vincent, 1993: VHF radar observations of gravity-wave production by cold fronts over southern Australia. J. Atmos. Sci., 50, 785-806.

—, I. Hirota, and W. K. Hocking, 1995: Gravity wave and equatorial wave morphology of the stratosphere derived from long-term rocket soundings. Quart. J. Roy. Meteor. Soc., 121, 149-186.

Fels, S. B., 1985: Radiative-dynamical interactions in the middle atmosphere. Advances in Geophysics, Vol. 28A, Academic Press, 277-300.

— J. D. Mahlman, M. D. Schwarzkopf, and R. W. Sinclair, 1980: Stratospheric sensitivity to perturbations in ozone and carbone dioxide: Radiative and dynamical responses. J. Atmos. Sci., 37, 2265-2297.

Fleming, E. L., S. Chandra, J. J. Barnett, and M. Corney, 1990: Zonal mean temperature, pressure, zonal wind and geopotential height as functions of latitude. Adv. Space Res., 10, 1211-1259.

Fritts, D. C., and G. D. Nastrom, 1992: Sources of mesoscale variability of gravity waves. Part II: Frontal, convective, and jet stream excitation. J. Atmos. Sci., 49, 111-127.

Gates, W. L., 1992: AMIP: The Atmospheric Model Intercomparison Project. Bull. Amer. Meteor. Soc., 73, 1962-1970.

Griffiths, M., and M. J. Reeder, 1996: Stratospheric inertia-gravity waves generated in a numerical model of frontogenesis. I: Model solutions. Quart. J. Roy. Meteor. Soc., 122, 1153-1174.

Hamilton, K., 1991: Climatological statistics of stratospheric inertiagravity waves deduced from historical rocketsonde wind and temperature data. J. Geophys. Res., 96, 20 831-20 839.

— R. J. Wilson, and R. S. Hemler, 1999: Middle atmosphere simulated with high vertical and horizontal resolution versions of a GCM: Improvements in the cold pole bias and generation of a QBO like oscillation in the Tropics. J. Atmos. Sci., 56, 3829-3846.

Haynes, P. H., C. J. Marks, M. E. McIntyre, T. G. Shepherd, and K P. Shine, 1991: On the "downward control" of extratropical diabatic circulations by eddy-induced mean zonal forces. J. Atmos. Sci., 48, 651-678.

Hines, C. O., 1997a: Doppler-spread parameterization of gravitywave momentum deposition in the middle atmosphere. Part 1: Basic formulation. J. Atmos. Sol. Terr. Phys., 59, 371-386.

_ 1997b: Doppler-spread parameterization of gravity-wave momentum deposition in the middle atmosphere. Part 2: Broad and quasi monochromatic spectra, and implementation. J. Atmos. Sol. Terr. Phys., 59, 387-400.

Hoskins, B. J., 1982: The mathematical theory of frontogenesis. Annu. Rev. Fluid Mech., 14, 131-151.

— , and P. J. Valdes, 1990: On the existence of storm-tracks. $J$. Atmos. Sci., 47, 1854-1864.

Kageyama, M., P. J. Valdes, G. Ramstein, C. Hewitt, and U. Wyputta, 1999: Northern Hemisphere storm tracks in present day and last glacial maximum climate simulations: A comparison of the European PMIP models. J. Climate, 12, 742-760.

Leovy, C. B., 1964: Simple models of thermally driven mesospheric circulation. J. Atmos. Sci., 21, 327-341.

Manzini, E., and N. A. McFarlane, 1998: The effect of varying the source spectrum of a gravity wave parameterization in a middle atmosphere general circulation model. J. Geophys. Res., 103, $31523-31539$.

_ , and J. Feichter, 1999: Simlation of the $\mathrm{SF}_{6}$ tracer with the middle atmosphere MAECHAM4 model: Aspects of the largescale transport. J. Geophys. Res., 104, 31 097-31 108.

, N. A. McFarlane, and C. McLandress, 1997a: Impact of the Doppler spread parameterization on the simulation of the middle atmosphere circulation using the MA/ECHAM4 general circulation model. J. Geophys. Res., 102, 25 751-25 762.

, — - and — , 1997b: Middle atmosphere simulations with the ECHAM4 model: Sensitivity to the Doppler spread gravity wave parameterization. Gravity Wave Processes: Their Parameterization in Global Climate Models, K. Hamilton, Ed., Springer-Verlag, 367-381.

McFarlane, N. A., 1987: The effect of orographically excited gravity wave drag on the general circulation of the lower stratosphere and troposphere. J. Atmos. Sci., 44, 1175-1800.

— C. McLandress, and S. Beagley, 1997: Seasonal simulations with the Canadian middle atmosphere model: Sensitivity to a combination of orographic and Doppler spread parameterizations of gravity wave drag. Gravity Wave Processes: Their Parameterization in Global Climate Models, K. Hamilton, Ed., SpringerVerlag, 351-366.

McLandress, C., 1997: Sensitivity studies using the Hines and Fritts gravity wave drag parameterizations. Gravity Wave Processes: Their Parameterization in Global Climate Models, K. Hamilton, Ed., Springer-Verlag, 245-256.

Medvedev, A. S., and G. P. Klaassen, 1995: Vertical evolution of gravity wave spectra and the parameterization of associated wave drag. J. Geophys. Res., 100, 25 841-25 853.

,-- and S. R. Beagley, 1998: On the role of an anisotropic gravity wave spectrum in maintaining the circulation of the middle atmosphere. Geophys. Res. Lett., 25, 509-512.

Miller, J. E., 1948: On the concept of frontogenesis. J. Meteor., 5, $169-171$.

Pawson, S., and Coauthors, 2000: The GCM-Reality Intercomparison Project for SPARC (GRIPS): Scientific issues and initial results. Bull. Amer. Meteor. Soc., 81, 781-796.

Randel, W. J., 1992: Global atmospheric circulation statistic, 1000$1 \mathrm{mb}$. National Center for Atmospheric Research Tech. Rep. TN$366+$ STR, $256 \mathrm{pp}$.

Reeder, M. J., and M. Griffiths, 1996: Stratospheric inertia-gravity waves generated in a numerical model of frontogenesis. II: Wave sources, generation mechanisms and momentum fluxes. Quart. J. Roy. Meteor. Soc., 122, 1175-1195.

Roeckner, E., and Coauthors, 1996: The atmospheric general circulation model ECHAM4: Model description and simulation of present-day climate. Max-Planck-Institut für Meteorologie MPI Rep. 218, 90 pp. 
Shepherd, T. G., K. Semeniuk, and J. N. Koshyk, 1996: Sponge layer feedback in middle atmosphere models. J. Geophys. Res., 101, 23 447-23 464.

Vincent, R. A., S. J. Allen, and S. D. Eckermann, 1997: Gravitywave parameters in the lower stratosphere. Gravity Wave Processes: Their Parameterization in Global Climate Models, K. Hamilton, Ed., Springer-Verlag, 7-25.
Warner, C. D., and M. E. McIntyre, 1996: On the propagation and dissipation of gravity wave spectra through a realistic middle atmosphere. J. Atmos. Sci., 53, 3213-3235.

__ and _ 1997: Gravity wave spectral models and the shapes of gravity wave spectra at low vertical wavenumbers. Gravity Wave Processes: Their Parameterization in Global Climate Models, K. Hamilton, Ed., Springer-Verlag, 217-226. 